\author{
Mengying Li \\ Department of Mechanical Engineering \\ and Applied Mechanics, \\ University of Pennsylvania, \\ Philadelphia, PA 19104-6315

Noam Lior
Department of Mechanical Engineering
and Applied Mechanics,
University of Pennsylvania,
Philadelphia, PA 19104-6315
e-mail: Iior@seas.upenn.edu

\section{Analysis of Hydraulic Fracturing and Reservoir Performance in Enhanced Geothermal Systems}

\begin{abstract}
Analyses of fracturing and thermal performance of fractured reservoirs in engineered geothermal system (EGS) are extended from a depth of $5 \mathrm{~km}$ to $10 \mathrm{~km}$, and models for flow and heat transfer in EGS are improved. Effects of the geofluid flow direction choice, distance between fractures, fracture width, permeability, radius, and number of fractures, on reservoir heat drawdown time are computed. The number of fractures and fracture radius for desired reservoir thermal drawdown rates are recommended. A simplified model for reservoir hydraulic fracturing energy consumption is developed, indicating it to be 51.8-99.6 MJ per $\mathrm{m}^{3}$ fracture for depths of 5-10 km. [DOI: 10.1115/1.4030111]
\end{abstract}

Keywords: geothermal energy, engineered geothermal systems (EGS), energy use for hydraulic fracturing, flow and heat transfer in EGS reservoir, number and radius of fractures for thermal drawdown

\section{Introduction: Background and Assumptions}

Geothermal energy is renewable, abundant, and comparatively clean and sustainable [1], with a long-term potential estimated to be more than 200,000-fold of current world energy demand [2], it is often available at a steady supply rate and is thus much more usable for base-load power generation than the intermittent and unsteady renewable resources such as wind and solar [1]. Geothermal energy used for power generation and direct-use heating applications currently accounts for approximately 2.1 EJ of worldwide energy and is forecast to have an annual growth of $10 \%$ [3].

Over $99 \%$ of the thermal heat within $10 \mathrm{~km}$ depth in the continental United States is available in hot dry rock (HDR) with low permeability $[2,4]$. A large volume of hot rocks (reservoir) should thus be fractured to increase fluid permeability, which is the so called EGS. Cold fluid ("geofluid," usually water) is injected into this reservoir to be heated by circulating it in the fractured reservoir. There are various ways to fracture the rock, including conventional explosives (nuclear was also proposed by some), but right now the most reasonable and manageable method is hydraulic fracturing, which is widely used for stimulating gas and oil fields, but in the EGS case it would typically be at bigger depths [2]. Hydraulic fracturing is performed by injection of high pressure water into the hot rock zone via a well drilled for that purpose, to propagate natural pores for creating enhanced fractures.

Reaching depths of 5-10 km and creating there a fractured reservoir for extracting the heat are very challenging tasks, both from the technology and optimal fracturing perspectives. The focal objective of this work is therefore to evaluate quantitatively the energy and heat extraction implications of creating and exploiting such deep HDR for the use of geothermal energy resources.

To that end, we calculate and analyze: (1) The energy needed for the fracturing, (2) The flow and heat transfer in the fractured reservoir, and (3) the effects of the selectable parameters, including fracture radius, width and permeability, spacing between fractures, number of fractures, and geofluid flow direction, on (1) and (2), all to draw recommendation for reservoir design.

The geothermal gradients examined ranged from $40^{\circ} \mathrm{C} / \mathrm{km}$ to $80^{\circ} \mathrm{C} / \mathrm{km}$. Nine cases are calculated, assuming that the earth

${ }^{1}$ Corresponding author.

Contributed by the Advanced Energy Systems Division of ASME for publication in the Journal of Energy Resources Technology. Manuscript received February 9 , 2015; final manuscript received February 25, 2015; published online April 22, 2015. Editor: Hameed Metghalchi. surface temperature is $15^{\circ} \mathrm{C}$ [5], which are summarized in Table 1. The average reservoir temperature is

$$
\bar{T}_{\mathrm{r}, \infty}=15+\bar{Z}_{\mathrm{r}} \cdot \mathrm{Th}_{\mathrm{g}}
$$

When liquid is injected into the EGS reservoir, it is preferred to keep it the liquid phase throughout the subsequent heating and recovery process, rather than allowing it to flash or otherwise evaporate, as explained in Refs. [4] and [6]. To accomplish this, the pressure in the subsurface system must be high enough to keep the hot liquid below its boiling point.

For EGS resource, higher temperature of produced geofluid will bring more energy to the surface. It is also obvious that this may require larger and more suitably fractured reservoirs, all of which require more energy consumption. Consequently, we proceed (in Sec. 2) to develop a model for calculating the energy consumption of hydraulic fracturing. In Sec. 3, we modify a commonly used EGS reservoir simulation model to examine the reservoir performance with respect to fracture characteristics. Other commercial programs for EGS reservoir simulation are also available, such as the TOUGH2 and TETRAD codes [7]. The results and conclusions are summarized in Sec. 4. The contribution of this work is to examine quantitatively the energy input and output for a typical EGS reservoir. The energy input is the enhanced reservoir hydraulic fracturing energy consumption. The energy output is the heat extracted from the reservoir. The temperature and pressure change of geofluid flowing through the enhanced reservoir are calculated by a finite element model. In more detail:

(1) Our calculations extend prior analyses from $5 \mathrm{~km}$ to $10 \mathrm{~km}$.

(2) Available models for flow and heat transfer in enhanced reservoirs are improved and expanded to include both subcritical and supercritical geofluid, buoyancy effects, and consideration of both upward and downward flows in them.

(3) The reservoir hydraulic fracturing energy consumption is not available in the literature, and this study develops a simplified mathematical model for that and offers estimates of fracturing energy consumption.

\section{Modeling and Analysis of Hydraulic Fracturing Energy Consumption}

The hydraulic fracturing process is to create fractures in rocks by high pressure fluid. The fluids used in hydraulic fracturing could be oil-based, water-based, alcohol-based, and foams or 
Table 1 Reservoir average temperatures considered in this work

\begin{tabular}{lccc}
\hline \hline & \multicolumn{3}{c}{$\begin{array}{c}\text { Average thermal } \\
\text { gradient } \mathrm{Th}_{\mathrm{g}}\left({ }^{\circ} \mathrm{C} / \mathrm{km}\right)\end{array}$} \\
\cline { 2 - 4 } & 40 & $\begin{array}{c}60 \\
\text { Average temperature } \\
\text { Average depth } \\
\text { of reservoir } \bar{Z}_{\mathrm{r}}(\mathrm{km})\end{array}$ & 80 \\
\hline 5 & & 315 & 415 \\
7.5 & 215 & 465 & 615 \\
10 & 315 & 615 & 815 \\
\hline \hline
\end{tabular}

emulsions [8]. In this study, we chose for simplicity pure water as the fracturing fluid.

2.1 Underground Rock Stress. For simplest conditions, a part of the earth's crust is assumed to have no appreciable forces acting upon the rock other than gravity; the rock is all under compressive stress [9]. The stress in the rock at point $A$ is shown in Fig. 1, where the vertical compressive stress (lithostatic pressure) at depth $\bar{Z}_{\mathrm{r}}$ is represented by the vector $S_{\mathrm{L}}$ while the horizontal compressive stress at $A$ is represented by $S_{\mathrm{H}}$. $S_{\mathrm{L}}$ can be calculated [9] by

$$
S_{\mathrm{L}}=\rho_{\mathrm{r}} g \bar{Z}_{\mathrm{r}}
$$

where $\rho_{\mathrm{r}}$ is the average density of rock above the point $A, \mathrm{~kg} / \mathrm{m}^{3}$, and $g$ is the gravitational acceleration, $9.8 \mathrm{~m} / \mathrm{s}^{2}$.

The horizontal stress is calculated as

$$
S_{\mathrm{H}}=\frac{S_{\mathrm{L}} \nu}{1-\nu}
$$

where $\nu$ is Poisson's ratio of rock material.

The fracturing process must overcome the in situ horizontal stress, $\sigma_{\mathrm{H}}=2 S_{\mathrm{H}}$. Since fractures propagate in the direction normal to the plane of least principal stress [10], when $\sigma_{\mathrm{H}}>S_{\mathrm{L}}$, the open orientation of a fracture will be vertical and propagating horizontally. Otherwise, the fracture will be opened horizontally and propagates in the vertical direction [9]. We assume and it is reasonable to expect that the rock will be homogenous granite for depths over $5 \mathrm{~km} \mathrm{[2]} \mathrm{and} \mathrm{the} \mathrm{Poisson's} \mathrm{ratio} \nu$ of granite is taken as 0.25 [11], hence $\sigma_{\mathrm{H}}<S_{\mathrm{L}}$. We therefore consider that the fractures would be open horizontally and propagate vertically, as is indeed observed to be true in current EGS sites [2].

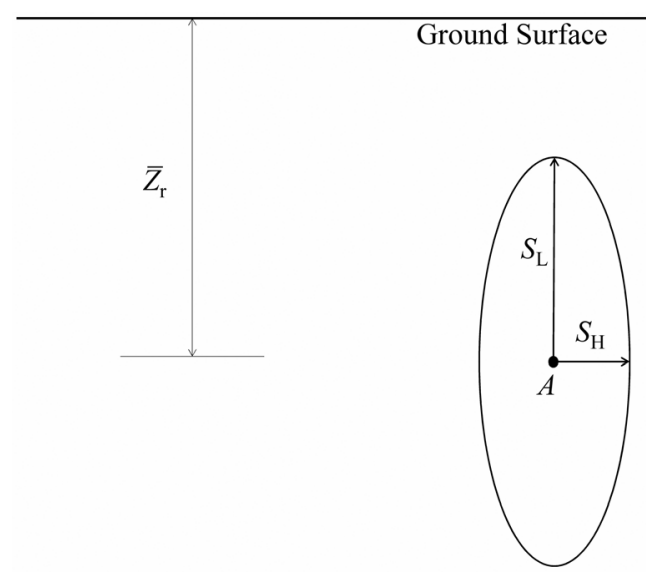

Fig. 1 Ellipse of stress for underground rock, $S_{L}$ is the vertical compressive stress, $S_{H}$ is the horizontal compressive stress, and $Z_{\mathrm{r}}$ is the depth of point $A$
The fracturing process is to inject high pressure fluid through the injection well to initiate a crack underground. The pressure $P_{\mathrm{hf}}$ applied at point $A$ needs to satisfy [9]

$$
P_{\mathrm{hf}} \geq \sigma_{\mathrm{H}}+S_{\mathrm{t}}
$$

where $S_{\mathrm{t}}$ is the effective tensile breaking strength of the rock. When this condition is satisfied, a crack will be initiated at point $A$ and be enlarged by propagating vertically. We simplify the fractures to be vertical-parallel fractures in this work, as shown in Fig. 2. The fractures are created sequentially: e.g., the right-most fracture is created first. After it reaches the desired size, the section of the injection well before that fracture is plugged to create the next fracture [9]. The process is repeated until the desired number of fractures is created.

2.2 Two-Dimensional (2D) Fracture Propagation Model. The two aspects of the fracturing process that need to be modeled are crack initiation and crack propagation [9]. The current experience of EGS reservoir fracturing shows that new cracks cannot be created [2]. So the fracturing process is actually the enlargement of existing cracks and faults [2]. The theoretical problem thus becomes modeling of the crack propagation only [9]. Besides, we assume that initiation at a given site has already occurred and that the principal stress orientations and magnitudes are known [9]. The rock failure in fracturing process is a complex thermal, hydrological, and mechanical coupling process, especially in EGS fields where high temperature is encountered [2]. Models that consider the coupling process were developed recently, such as in Refs. [12-14]. In this work, we adapted a simpler linearly propagating model for analyzing the fracturing process.

The linearly propagating rectangular shape fractures depicted in Fig. 2(a) appear often in oil and gas applications because the oil and gas are usually present with distinct boundaries (horizontal lithological bounds) in a reservoir [9], and hence the height $H$ of a fracture equals to the reservoir height [15]. However, in EGS application, the reservoir is mostly artificial with no distinct reservoir boundaries. Fracturing will occur in an approximately homogeneous region of hot rock, so a radially symmetric fracture that propagates outward from the borehole is more suitable for simulating an EGS reservoir (shown in Fig. 2(b)). Figure 3 is the schematic representation of a radially propagating fracture.

The Geertsma and De Klerk model (GdK model) [16] is widely used for modeling linear propagation of $2 \mathrm{D}$ hydraulic fracture. In this work, we assume:

(1) The fracturing fluid flow is laminar (proven in Sec. 3) Newtonian flow (water).

(2) Fluid pressure at fracture tip (point where the fracturing will not propagating any further) equal to $\sigma_{\mathrm{H}}$.

(3) The fracture walls deformation is linear elastic.

(4) The effective rock tensile strength $S_{\mathrm{t}} \sim 0$ [17].

(5) No fluid loss during the fracturing process.

Under these assumptions, the GdK model [9] offers the following equations that predict the time-dependent dimensions of radially propagating fractures:

$$
\begin{gathered}
R\left(t_{\mathrm{hf}}\right)=\left[\frac{15}{16 \pi}\left(\frac{G}{\mu_{\mathrm{hf}} \dot{q}_{\mathrm{hf}}}\right)^{0.25} \dot{q}_{\mathrm{hf}} t_{\mathrm{hf}}\right]^{0.444} \\
w\left(0, t_{\mathrm{hf}}\right)=2.15\left[\frac{(1-\nu) \mu_{\mathrm{hf}} \dot{q}_{\mathrm{hf}} R\left(t_{\mathrm{hf}}\right)}{G}\right]^{0.25} \\
P_{\mathrm{hf}}\left(t_{\mathrm{hf}}\right)-\sigma_{\mathrm{H}}=-\frac{5}{2 \pi}\left(\frac{G^{3} \mu_{\mathrm{hf}} \dot{q}_{\mathrm{hf}}}{R\left(t_{\mathrm{hf}}\right)^{3}}\right)^{0.25} \ln \left(\frac{r_{\mathrm{iw}}}{R\left(t_{\mathrm{hf}}\right)}\right)
\end{gathered}
$$

where $R$ is the radius of fracture, $\mathrm{m} ; G$ is the shear modulus of rock, $\mathrm{Pa} ; \mu_{\mathrm{hf}}$ is the viscosity of fracturing fluid, Pa.s; $\dot{q}_{\mathrm{hf}}$ is the 

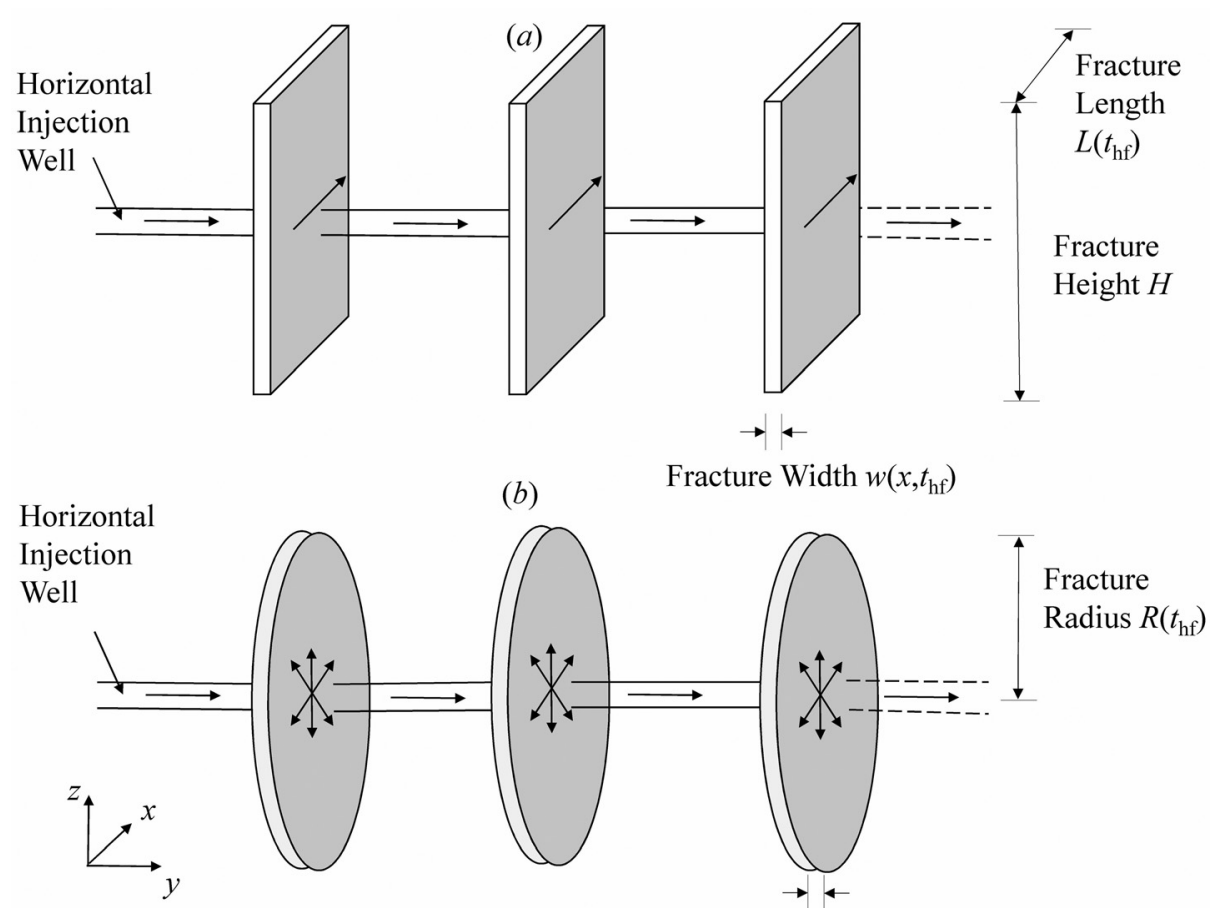

Fracture Width $w\left(r, t_{\mathrm{hf}}\right)$

Fig. 2 Vertical propagation of fractures: (a) linearly propagating rectangular shape fracture and $(b)$ radially propagating cylindrical shape fracture (modified from Ref. [9])

volume flow rate of fracturing fluid, $\mathrm{m}^{3} / \mathrm{s} ; t_{\mathrm{hf}}$ is the hydraulic fracturing treatment time, $\mathrm{s} ; w$ is the width of fracture, $\mathrm{m} ; \nu$ is the Poisson's ratio of rock material; $P_{\mathrm{hf}}$ is the pressure applied to fracture rocks, $\mathrm{Pa} ; \sigma_{\mathrm{H}}$ is the in situ horizontal stress, $\mathrm{Pa}$; and $r_{\mathrm{iw}}$ is the radius of injection wellbore, $\mathrm{m}$.

According to Ref. [15], the average width of the fracture is

$$
\bar{w}\left(t_{\mathrm{hf}}\right)=\frac{8}{15} w\left(0, t_{\mathrm{hf}}\right)
$$

The energy consumption of hydraulic fracturing is considered to be the hydraulic (here geothermal) pumping electricity consumption. It is calculated as

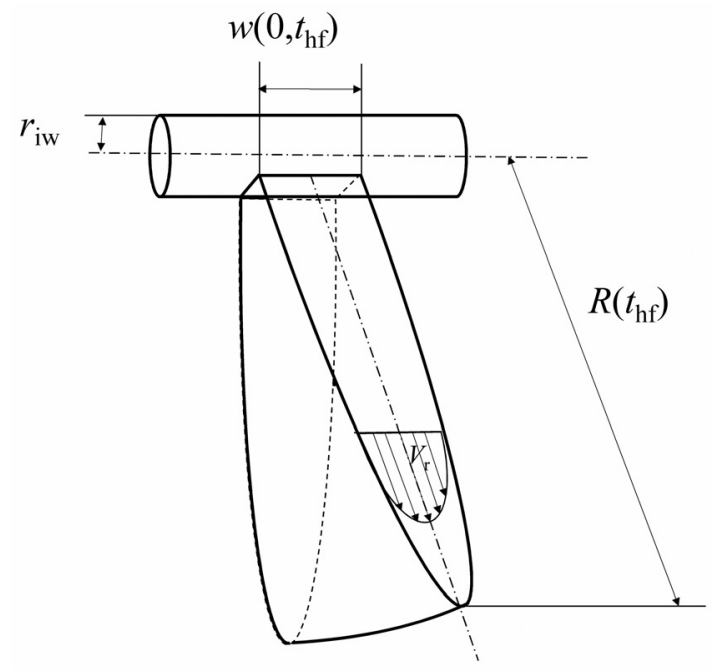

Fig. 3 Schematic representation of radially propagating fracture with laminar fluid flow (modified from Ref. [15]). $R$ is the radius of fracture, $w$ is the fracture width, $r_{\text {iw }}$ is the radius of injection wellbore, and $V_{r}$ is the fracturing fluid velocity.

$$
W_{\mathrm{hf}}=\int_{0}^{t_{\mathrm{hf}}} \frac{\dot{q}_{\mathrm{hf}}\left(P_{\mathrm{hf}}(\tau)+\Delta P_{\mathrm{IW}}-P_{\mathrm{r}, \mathrm{hp}}\right)}{\eta_{\mathrm{p}}} d \tau
$$

where $\Delta P_{\text {IW }}$ is the friction pressure loss when fracturing fluid flow through injection well, $\mathrm{Pa} ; P_{\mathrm{r}, \mathrm{hp}}$ is the hydrostatic pressure at reservoir depth, $P_{\mathrm{r}, \mathrm{hp}}=\rho_{0} g \bar{Z}_{\mathrm{r}}, \mathrm{Pa}$; and $\eta_{\mathrm{p}}$ is the hydraulic fracturing pump efficiency, $\%$.

Since the friction pressure loss of fluid in the injection well $\Delta P_{\text {IW }} \ll P_{\text {r,hp }}$, we could eliminate $\Delta P_{\text {IW }}$ from Eq. (9). Using Eqs. (5)-(9), we could get the relations between fracture dimensions and pumping energy consumption.

2.3 Assumptions for Modeling and Analysis. We assume that the EGS reservoir is located in homogenous granite region underground. The rocks that need to be fractured are isotropic granite. The fracturing fluid is assumed to be pure water injected at $15^{\circ} \mathrm{C}$. The shear modulus of material is calculated as

$$
G=\frac{E}{2(1+\nu)}
$$

where $E$ is Young's modulus of rock material, Pa.

All assumptions of parameters used in the calculation are listed in Table 2.

2.4 Energy Consumption to Create a Single Fracture. MATLAB 2012a software [18] is used to solve Eqs. (5)-(9), and the results are presented below.

Figure 4(a) presents the fracture radius $R$ with respect to hydraulic treatment time $t_{\mathrm{hf}}$ at flow rates $\dot{q}_{\mathrm{hf}}=0.05 \mathrm{~m}^{3} / \mathrm{s}, 0.1 \mathrm{~m}^{3} / \mathrm{s}$, and $0.15 \mathrm{~m}^{3} / \mathrm{s}$. Figure $4(b)$ presents the fracture average width $\bar{w}$ with respect to hydraulic treatment time $t_{\mathrm{hf}}$ at flow rates $\dot{q}_{\mathrm{hf}}=0.05$ $\mathrm{m}^{3} / \mathrm{s}, 0.1 \mathrm{~m}^{3} / \mathrm{s}$, and $0.15 \mathrm{~m}^{3} / \mathrm{s}$. For given treatment times, higher flow rates result in larger fracture radii, but the width increases at a slower rate as time increases. 
The time-dependent volume of a fracture can be calculated by

$$
V_{\mathrm{hf}}\left(t_{\mathrm{hf}}\right)=\pi R\left(t_{\mathrm{hf}}\right)^{2} \bar{w}\left(t_{\mathrm{hf}}\right)
$$

Figure 4(c) presents the fracturing energy consumption with respect to fracture volume at fracturing flow rates $\dot{q}_{\mathrm{hf}}=0.05 \mathrm{~m}^{3} / \mathrm{s}$, $0.1 \mathrm{~m}^{3} / \mathrm{s}$, and $0.15 \mathrm{~m}^{3} / \mathrm{s}$. The considered reservoir average depths $\bar{Z}_{\mathrm{r}}$ are $5 \mathrm{~km}, 7.5 \mathrm{~km}$, and $10 \mathrm{~km}$. From data regression, we get

$$
W_{\mathrm{hf}}=K_{\mathrm{hf}} \cdot V_{\mathrm{hf}}
$$

The parameter $K_{\mathrm{hf}}$ differs with reservoir depth. Its value is listed in Table 3. Deeper reservoirs consume more energy for fracturing because a larger in situ horizontal stress $\sigma_{\mathrm{H}}$ must be overcome.

Having calculated the energy needed to create a single fracture in this section, we examine in the following Sec. 3 the amount of heat that can be extracted by the geofluid flowing through the stimulated fractures.

\section{Modeling and Analysis of Flow and Heat Transfer in an EGS Reservoir}

As described above, the parallel cylindrical fractures are created sequentially. After creation of the desired number of fractures, the original horizontal injection wellbore (Fig. 2) is plugged and abandoned. Then, new injection and production wellbores are drilled to connect the fractures and create a flow path for the geofluid. To allow the geofluid to sweep largest hot rock surfaces, the injection well and production well are at the uppermost and bottom of the fracture.

3.1 Mathematical Model. In deep EGS application, the permeability of natural rock is as low as $10^{-18}[13,19-21]$, assuming that the rock is isotropic granite with little nature porosity. In this section, we assume that the fractures in the EGS reservoir are parallel, as shown in Fig. 5. The shape of the fractures is assumed to be thin-cylindrical of uniform width $\bar{w}$. In Fig. $5, T_{\text {in }}$ and $T_{\text {out }}$ represent the geofluid temperature at reservoir inlet and outlet, respectively. $2 F_{\mathrm{s}}$ is the separation distance between fractures, and $L_{\text {in }}$ and $L_{\text {out }}$ are the geofluid inlet and outlet length in a fracture. The arrows indicate schematically the geofluid flow direction. The geofluid flow scheme is adapted from Refs. [10] and [23]. Different from Refs. [10] and [23], the geofluid in this model could flow upward from the bottom of fracture to the top or flow downward from the top to the bottom, where the flow direction in Fig. 5 will reverse.

One-quarter of single hot rock block is simulated due to the symmetry in $x$ and $y$ directions. The mesh scheme and orientations of coordinates are presented in Fig. 6 .

3.2 Model of the Hot Rock Block. Heat transfer within the rocks satisfies the three-dimensional (3D) heat conduction equation

$$
\frac{\partial T_{\mathrm{r}}}{\partial t}=\alpha_{\mathrm{r}}\left(\frac{\partial^{2} T_{\mathrm{r}}}{\partial x^{2}}+\frac{\partial^{2} T_{\mathrm{r}}}{\partial y^{2}}+\frac{\partial^{2} T_{\mathrm{r}}}{\partial z^{2}}\right)
$$

where $\alpha_{\mathrm{r}}=k_{\mathrm{r}} / \rho_{\mathrm{r}} \cdot c_{\mathrm{r}}$ is the thermal diffusivity of rocks.

The initial condition is

$$
T_{\mathrm{r}}(x, y, z, 0)=T_{\mathrm{r}, \infty}
$$

At boundary surface 1

$$
-2 k_{\mathrm{r}} \frac{\partial T_{\mathrm{r}}(x, 0, z, t)}{\partial y}=\dot{q}
$$

where $\dot{q}$ is the heat flux into the geofluid from the interface of rock and geofluid, which is then coupled with the overall flow and heat transfer model of the geofluid. The factor "2" on the lefthand side of Eq. (15) accounts for the fact that a fracture has two faces.

At surfaces $\mathbf{2}$ and $\mathbf{4}$, a symmetry boundary condition applies and at boundary surface $\mathbf{3}$, it is assumed that there is no heat transfer to or from surroundings, which means the geofluid sweeping the rock surface takes away only the heat stored in the rock blocks depicted as shaded in Fig. 5. Therefore, at surfaces 2, 3, and 4

$$
\mathbf{n} \cdot \nabla T_{\mathrm{r}}=0
$$

3.2.1 The Model of the Geofluid Flow and Heat Transfer. The width of fracture $\bar{w}$ is often of the order of millimeters and very small compared to the radius of the fracture $R$ (Fig. 4). Then, we could make the simplification that the flow in a fracture is $2 \mathrm{D}$ (this assumption was also made in Ref. [9] and used in the COMSOL 4.3a subsurface flow module [24]). The temperature gradient of the geofluid in the $y$ direction is therefore ignored, and thus

$$
T(x, z, t)=T_{\mathrm{r}}(x, 0, z, t)
$$

indicating that the geofluid temperature equals to the temperature of rock/geofluid interface.

The $2 \mathrm{D}$ conservation of mass of the geofluid is

$$
\frac{\partial \rho}{\partial t}+\frac{\partial(\rho U)}{\partial x}+\frac{\partial(\rho V)}{\partial z}=0
$$

The geofluid (liquid) in the reservoir is assumed to be incompres-

\begin{tabular}{|c|c|c|c|c|c|}
\hline Parameters & Symbol & & Value & & Unit \\
\hline Viscosity of fracturing fluid at $15^{\circ} \mathrm{C}$ & $\mu_{\mathrm{hf}}$ & & $1.14 \times 10^{-3}[29]$ & & $\mathrm{Pa} \cdot \mathrm{s}$ \\
\hline The Young's modulus of granite rock & $E$ & & $55[17]$ & & $\mathrm{GPa}$ \\
\hline Gravitational acceleration & $G$ & & 9.8 & & $\mathrm{~m} / \mathrm{s}^{2}$ \\
\hline Volume flow rate of fracturing & $\dot{q}_{\mathrm{hf}}$ & & Variable & & $\mathrm{m}^{3} / \mathrm{s}$ \\
\hline Radius of injection wellbore & $r_{\mathrm{iw}}$ & & 8.5 & & in. \\
\hline Hydraulic fracturing treatment time & $t_{\mathrm{hf}}$ & & Variable & & $\mathrm{s}$ \\
\hline Average depth of reservoir & $\bar{Z}_{\mathrm{r}}$ & 5000 & 7500 & 10,000 & $\mathrm{~m}$ \\
\hline Hydrofracturing pump efficiency & $\eta_{\mathrm{p}}$ & & 80 & & $\%$ \\
\hline Poisson's ratio of granite & $\nu$ & & $0.25[11]$ & & - \\
\hline In situ horizontal rock stress, perpendicular to fracture surface & $\sigma_{\mathrm{H}}$ & 86.7 & 130.0 & 173.4 & $\mathrm{MPa}$ \\
\hline
\end{tabular}
sible and its density is notated as $\rho$, evaluated at the temperature $T_{\text {ref }}=\left(T_{\text {in }}+\bar{T}_{\mathrm{r}, \infty}\right) / 2$ and pressure $P_{\text {ref }}=\rho_{\text {in }} g \bar{Z}_{\mathrm{r}}$. Other geofluid properties such as $\mu$ (average dynamic viscosity), $\alpha$ (average thermal diffusivity), $c$ (average specific heat), and $\beta_{\mathrm{T}}$ (average thermal expansion coefficient) are all evaluated at $T_{\text {ref }}$ and $P_{\text {ref. }}$.

The mass conservation equation thus reduces to

Table 2 Assumptions of parameters in hydraulic fracturing calculation for reservoirs of different depths 
(a)

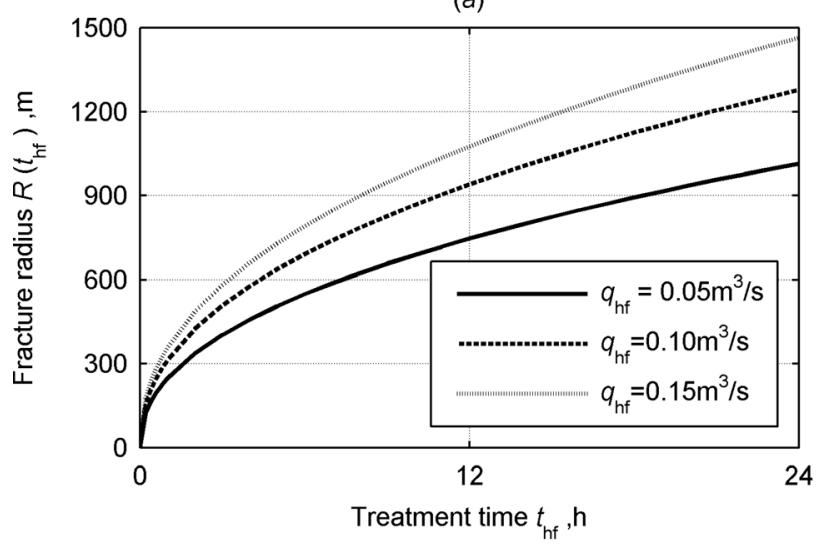

(b)

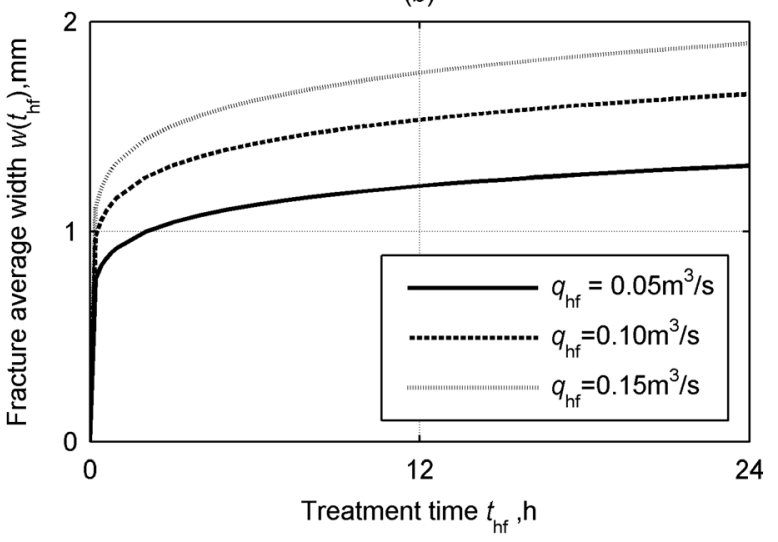

(c)

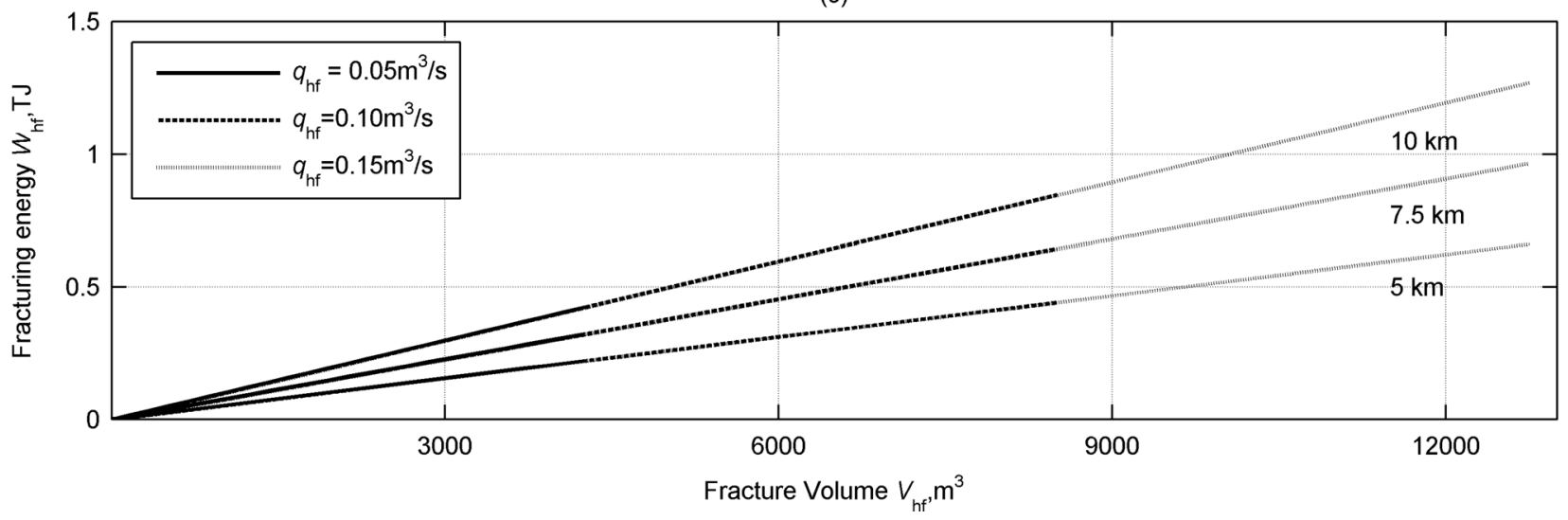

Fig. 4 Fracture radius $R(a)$ and average width $\bar{w}(b)$ with respect to treatment time $t_{\mathrm{h} f}$, and $(c)$ fracturing energy consumption $W_{\mathrm{hf}}$ with respect to fracture volume $V_{\mathrm{hf}}$ at flow rates $\dot{q}_{\mathrm{hf}}=0.05 \mathrm{~m}^{3} / \mathrm{s}, 0.1 \mathrm{~m}^{3} / \mathrm{s}$, and $0.15 \mathrm{~m}^{3} / \mathrm{s}$, for reservoirs with depths $\bar{Z}_{\mathrm{r}}=5 \mathrm{~km}$, $7.5 \mathrm{~km}$, and $10 \mathrm{~km}$

$$
\frac{\partial U}{\partial x}+\frac{\partial V}{\partial z}=0
$$

The geofluid conservation of energy equation is

$$
\frac{\partial T}{\partial t}+\frac{\partial(T U)}{\partial x}+\frac{\partial(T V)}{\partial z}=\alpha\left(\frac{\partial^{2} T}{\partial x^{2}}+\frac{\partial^{2} T}{\partial z^{2}}\right)+\frac{\dot{q}}{\rho c \bar{w}}
$$

where the heat flux $\dot{q}$ from rock to geofluid is a heat source of the geofluid.

The conservation of momentum equations for the geofluid are

$$
\begin{aligned}
\rho\left(\frac{\partial U}{\partial t}+\frac{\partial(U U)}{\partial x}+\frac{\partial(V U)}{\partial y}\right)= & -\frac{\partial P}{\partial x}+\mu\left(\frac{\partial^{2} U}{\partial x^{2}}+\frac{\partial^{2} U}{\partial y^{2}}\right) \\
\rho\left(\frac{\partial V}{\partial t}+\frac{\partial(U V)}{\partial x}+\frac{\partial(V V)}{\partial y}\right)= & -\frac{\partial P}{\partial y}+\mu\left(\frac{\partial^{2} V}{\partial x^{2}}+\frac{\partial^{2} V}{\partial y^{2}}\right) \\
& -\rho g\left[1-\beta_{T}\left(T-T_{\text {ref }}\right)\right]
\end{aligned}
$$

The buoyancy effect is considered using the modified gravity acceleration $g \cdot\left[1-\beta_{\mathrm{T}}\left(T-T_{\text {ref }}\right)\right]$.

The flow in the fracture is laminar because the Reynolds number is $\operatorname{Re}=V \cdot\left(L_{\text {in }} \bar{w}\right) /\left(2 L_{\text {in }}+2 \bar{w}\right) / \nu \sim 10^{-2} \times 10^{-3} /$ $10^{-7} \sim 100<2000$. For laminar viscous flow in thin fractures, the momentum equations could be simplified to Darcy's law [23]

Table $3 K_{\mathrm{hf}}$ with respect to reservoir depth

\begin{tabular}{lccc}
\hline \hline Reservoir depth $\bar{Z}_{\mathrm{r}}(\mathrm{km})$ & 5 & 7.5 & 10 \\
\hline$K_{\mathrm{hf}} \cdot 10^{5}\left(\mathrm{TJ} / \mathrm{m}^{3}\right)$ & 5.1779 & 7.5672 & 9.9566 \\
\hline \hline
\end{tabular}

Journal of Energy Resources Technology

$$
\begin{gathered}
-\frac{\partial P}{\partial x}=\frac{\mu}{k_{\mathrm{f}}} U \\
-\left(\frac{\partial P}{\partial z}+\rho g\left(1-\beta_{\mathrm{T}}\left(T-T_{\mathrm{ref}}\right)\right)\right)=\frac{\mu}{k_{\mathrm{f}}} V
\end{gathered}
$$

where the permeability of fractured reservoir $k_{\mathrm{f}}$ is of order $0.01-1$ Darcy $\left(1\right.$ Darcy $=10^{-12} \mathrm{~m}^{2}$ ) [13,20,25-27]. The permeability of fractured reservoir is a function of fracture width. References [9] and [23] use a simple relation that $k_{\mathrm{f}}=\bar{w}^{2} / 12$, Ref. [25] gives more detailed correlation between $k_{\mathrm{f}}$ and $\bar{w}$. In this work, we examine the effect of $k_{\mathrm{f}}$ independently of $\bar{w}$ because other factors may influence its value too.

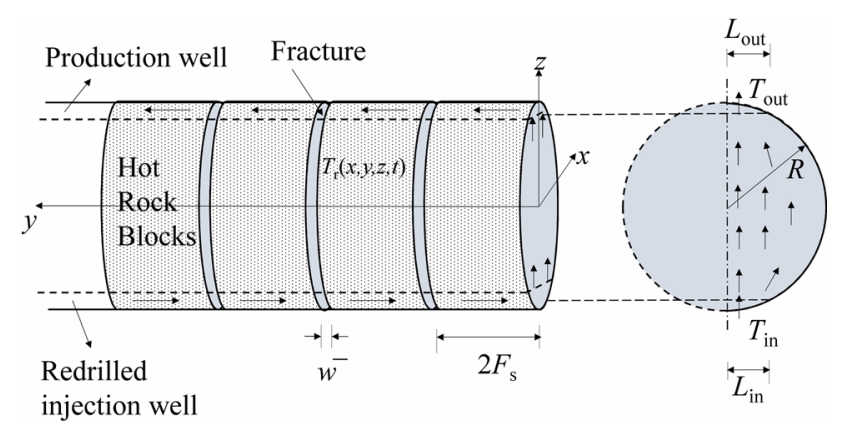

Fig. 5 Scheme of flow in the modeled EGS reservoir with parallel radial fractures. The cross-sectional sketch on the right shows computed typical velocity vectors inside a fracture (modified from Ref. [22]). 
The initial condition of velocities is $U=0$ and $V=0$.

At boundary $\mathbf{1}^{\prime}, U=0$ and $V=0$, corresponding to no slip on the walls.

At boundary $\mathbf{2}^{\prime}, V=0.5 \dot{m}_{\mathrm{f}} /\left(\rho_{\text {in }} \cdot \bar{w} L_{\text {in }}\right)$ and $U=0$, corresponding to geofluid inflow. $\dot{m}_{\mathrm{f}}$ is the mass flow rate of geofluid in each fracture, $\dot{m}_{\mathrm{f}}=\dot{m} / N_{\mathrm{f}}, \mathrm{kg} / \mathrm{s} ; \dot{m}$ is the mass flow rate of geofluid in reservoir, $\mathrm{kg} / \mathrm{s} ; N_{\mathrm{f}}$ is the number of fractures. In addition, there is an edge temperature constraint that when $t>0, T(t)=T_{\mathrm{r}}(t)=T_{\mathrm{in}}$.

At boundary $\mathbf{3}^{\prime}$, a symmetry boundary condition with respect to $x$ applies.

At boundary $4^{\prime}, P=P_{\text {out }}$, corresponding to the geofluid outflow condition, where $P_{\text {out }}$ is the geofluid pressure at reservoir outlet.

3.2.2 Nondimensional Form. To simplify the above equations, they are recast into dimensionless form; Define dimensionless parameters $\tilde{t}=t \alpha_{\mathrm{r}} / F_{\mathrm{s}}, \quad \tilde{x}=x / R, \quad \tilde{y}=y / F_{\mathrm{s}}, \quad \tilde{z}=\left(z-\bar{Z}_{\mathrm{r}}\right) / R$, $\tilde{P}=\left(P-P_{\text {out }}\right) / P^{*}, \tilde{U}=U / V^{*}, \tilde{V}=V / V^{*}, \tilde{T}=\left(T-T_{\text {in }}\right) /\left(\bar{T}_{\mathrm{r}, \infty}-T_{\text {in }}\right)$, $\tilde{T}_{\mathrm{r}}=\left(T_{r}-T_{\mathrm{in}}\right) /\left(\bar{T}_{\mathrm{r}, \infty}-T_{\mathrm{in}}\right)$, where $V^{*}$ is the inflow velocity in each fracture where $V^{*}=0.5 \dot{m}_{\mathrm{f}} /\left(\rho_{\text {in }} \cdot \bar{w} L_{\text {in }}\right) . P^{*}$ is a characteristic pressure related to Darcy's velocity drag, defined as $P^{*}=\bar{\mu} V^{*} R / k_{\mathrm{f}}$ (obtained from nondimensionalize Eq. (23)). $P_{\text {out }}$ is the pressure of the reservoir geofluid outlet, and $\bar{T}_{\mathrm{r}, \infty}$ is the average undisturbed reservoir rock temperature. All dimensionless parameters are of the order of 1 .

The dimensionless heat conduction equation of the hot rocks is

$$
\frac{\partial \tilde{T}_{\mathrm{r}}}{\partial \tilde{t}}=\frac{\partial^{2} \tilde{T}_{\mathrm{r}}}{\partial \tilde{y}^{2}}+\left(\frac{F_{\mathrm{s}}}{R}\right)^{2}\left(\frac{\partial^{2} \tilde{T}_{\mathrm{r}}}{\partial \tilde{x}^{2}}+\frac{\partial^{2} \tilde{T}_{\mathrm{r}}}{\partial \tilde{z}^{2}}\right)
$$

The initial condition is $\tilde{T}_{\mathrm{r}}(\tilde{x}, \tilde{y}, \tilde{z}, 0)=1-\tilde{z}\left(R \cdot T h_{\mathrm{g}} /\left(\bar{T}_{\mathrm{r}, \infty}-T_{\mathrm{in}}\right)\right)$.

At boundary surface 1, substitute $\dot{q}$ with Eqs. (15) and (20) and nondimensionalize

$$
\begin{gathered}
-\frac{\partial \tilde{T}_{\mathrm{r}}}{\partial \tilde{y}}=K_{1}\left[\frac{\partial\left(\tilde{T}_{\mathrm{r}} \tilde{U}\right)}{\partial \tilde{x}}+\frac{\partial\left(\tilde{T}_{\mathrm{r}} \tilde{V}\right)}{\partial \tilde{z}}+\frac{R \alpha_{\mathrm{r}}}{F_{\mathrm{s}}^{2} V^{*}} \frac{\partial \tilde{T}_{\mathrm{r}}}{\partial \tilde{t}}-\frac{\bar{\alpha}}{R V^{*}}\left(\frac{\partial^{2} \tilde{T}_{\mathrm{r}}}{\partial \tilde{x}^{2}}+\frac{\partial^{2} \tilde{T}_{\mathrm{r}}}{\partial \tilde{z}^{2}}\right)\right], \\
\text { where } K_{1}=\frac{F_{\mathrm{s}} \rho c \bar{w} V^{*}}{2 k_{\mathrm{r}} R}=\frac{F_{\mathrm{s}} \rho c}{2 k_{\mathrm{r}} R} \frac{\dot{m}}{2 N_{\mathrm{f}} \rho_{\mathrm{in}} L_{\mathrm{in}}}
\end{gathered}
$$

Since $R \alpha_{\mathrm{r}} / F_{\mathrm{s}}^{2} V^{*} \sim 10^{2} \times 10^{-6} / 10^{2} \times 10^{-1} \sim 10^{-5}$ and $\alpha / R V^{*} \sim 10^{-6}$ $/ 10^{2} \times 10^{-1} \sim 10^{-7}$, we could neglect the last two terms on the right side of above equation, so it reduces to

$$
-\frac{\partial \tilde{T}_{\mathrm{r}}}{\partial \tilde{y}}=K_{1}\left[\frac{\partial\left(\tilde{T}_{\mathrm{r}} \tilde{U}\right)}{\partial \tilde{x}}+\frac{\partial\left(\tilde{T}_{\mathrm{r}} \tilde{V}\right)}{\partial \tilde{z}}\right]
$$
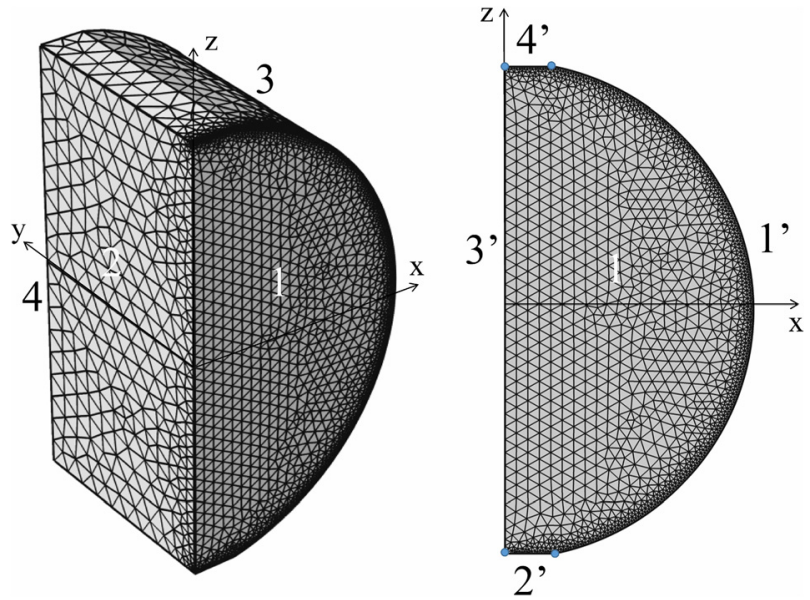

Fig. 6 The mesh scheme of model domain and coordinates used in the numerical simulation
Also at boundary surface 1, nondimensionalize Eq. (17)

$$
\tilde{T}(\tilde{x}, \tilde{z}, \tilde{t})=\tilde{T}_{\mathrm{r}}(\tilde{x}, 0, \tilde{z}, \tilde{t})
$$

At other boundary surfaces $\mathbf{2 , 3}$, and 4

$$
\mathbf{n} \cdot \nabla \tilde{T}_{\mathrm{r}}=0
$$

The dimensionless governing equations for the geofluid are

$$
\begin{gathered}
-\frac{\partial \tilde{P}}{\partial \tilde{x}}=\tilde{U} \\
-\left(\frac{\partial \tilde{P}}{\partial \tilde{z}}+\left(K_{2}-K_{3}(\tilde{T}-0.5)\right)\right)=\tilde{V} \\
\frac{\partial \tilde{U}}{\partial \tilde{x}}+\frac{\partial \tilde{V}}{\partial \tilde{z}}=0
\end{gathered}
$$

where

$$
\begin{gathered}
K_{2}=\rho g R / P^{*}=\bar{w} k_{\mathrm{f}} N_{\mathrm{f}} \frac{2 \rho g \rho_{\text {in }} L_{\text {in }}}{\dot{m} \mu} \\
K_{3}=K_{2} \beta_{\mathrm{T}}\left(\bar{T}_{\mathrm{r}, \infty}-T_{\text {in }}\right)
\end{gathered}
$$

Initially, $\tilde{U}=0$ and $\tilde{V}=0$.

At boundary $\mathbf{1}^{\prime}, \tilde{U}=0$ and $\tilde{V}=0$.

At boundary $\mathbf{2}^{\prime}, \tilde{U}=0$ and $\tilde{V}=1$ correspond to geofluid inlet condition, with temperature constraint $\tilde{T}=\tilde{T}_{\mathrm{r}}=0$.

At boundary $\mathbf{3}^{\prime}$, a symmetry boundary condition with respect to $\tilde{x}$ applies.

At boundary $4^{\prime}, \tilde{P}=0$, corresponding to geofluid outflow condition and a pressure constraint.

The rock temperature field $\tilde{T}_{\mathrm{r}}$ and geofluid flow field $\tilde{P}, \tilde{U}, \tilde{V}$ are coupled by Eqs. (27)-(34). We could therefore get $\tilde{T}_{\mathrm{r}}$ and $\tilde{P}$, $\tilde{U}, \tilde{V}$ by solving the coupled Partial Differential Equations (PDEs) listed above with corresponding initial conditions and boundary conditions.

The software used to solve the coupled PDEs is COMSOL MULTIPHYSICS 4.3a [24]. The geometric representation and the computation mesh are shown in Fig. 6. The mesh was refined on the rock/ geofluid interface domain (Surface 1) as well as along the geofluid flow boundaries (Edge $\mathbf{1}^{\prime}$ ).

3.3 Assumptions for Modeling and Analysis. Typically, geofluid flow rates of $50-150 \mathrm{~kg} / \mathrm{s}$ or more per production well are considered to be necessary for resulting in an economical geothermal electricity production rate [2]. In this work, we therefore assumed that $100 \mathrm{~kg} / \mathrm{s}$ geofluid is produced from the reservoir. With an assumption of $10 \%$ geofluid loss in the reservoir [2], $111 \mathrm{~kg} / \mathrm{s}$ geofluid needs to be injected. The total mass flow rate $\dot{m}$ in the reservoir is fixed to be $105.5 \mathrm{~kg} / \mathrm{s}$, which is the average value between the injection well flow rate $(111 \mathrm{~kg} / \mathrm{s})$ and the production wells flow rate $(100 \mathrm{~kg} / \mathrm{s})$.

All assumptions of fixed parameters used in the calculation are listed in Table 4. Reservoir based average thermal properties of the geofluid for nine calculated cases (Table 1) are listed in Table 5. The thermal properties of the geofluid, assumed to be water, are calculated from EES software "IPAWS_Steam" data base [29].

3.4 Sensitivity Analysis. In this section, we study the case of a $7.5 \mathrm{~km}$ reservoir with $60^{\circ} \mathrm{C} / \mathrm{km}$ thermal gradient as a calculation example to examine effects of key parameters on reservoir performance. The results are obtained by solving Eqs. (25)-(34) using the COMSOL 4.3a software.

Equations (27)-(34) show that the reservoir information (number of fracture, fracture radius, fracture width, etc.) enters the 
model by three parameters, $K_{1}, K_{2}$, and $K_{3}$. Equation (26) gives that $K_{1}$ is influenced by $F_{\mathrm{s}}, R$, and $N_{\mathrm{f}}$ for a given reservoir. Equations (33) and (34) show that $K_{2}$ and $K_{3}$ are influenced by $\bar{w}, k_{\mathrm{f}}$, and $N_{\mathrm{f}}$.

Therefore, the effects of six key parameters were examined and presented in Table 6: (1) flow direction: upward and downward in cases SC0 and SC1, respectively; (2) half the fracture separation distance $F_{\mathrm{S}}$, case $\mathrm{SC} 2$; (3) fracture radius $R$, case $\mathrm{SC} 3$; (4) number of fractures $N_{\mathrm{f}}$, case SC4; (5) fracture width $\bar{w}$, case SC5; and (6) fracture permeability $k_{\mathrm{f}}$, case SC6.

Case SC0 is the base case where fluid flows upward, $F_{\mathrm{s}}=60 \mathrm{~m}$, $R=500 \mathrm{~m}, N_{\mathrm{f}}=5, \bar{w}=2 \mathrm{~mm}$, and $k_{\mathrm{f}}=10^{-13} \mathrm{~m}^{2}$.

The heat production rate of the reservoir $Q_{\mathrm{r}}$ is proportional to the dimensional reservoir outlet geofluid temperature $\tilde{T}_{\text {out }}$, expressed by

$$
\dot{Q}_{\mathrm{r}}=\dot{m} c\left(\bar{T}_{\mathrm{r}, \infty}-T_{\mathrm{in}}\right) \tilde{T}_{\mathrm{out}}
$$

For a given reservoir, $\tilde{T}_{\text {out }}$ is the only variable in Eq. (35). So $\tilde{T}_{\text {out }}$ is used as a comparison criterion to examine the effect of these six parameters.

Define the dynamic pressure of geofluid in reservoir subtract reservoir outlet pressure as the relative dynamic pressure $\hat{P}_{\mathrm{d}}$ as

$$
\hat{P}_{\mathrm{d}}=\tilde{P} P^{*}+\rho g R\left(\tilde{z}-\tilde{z}_{\text {out }}\right)
$$

which indicates the combination effect of friction and buoyancy of geofluid in fractures. The reservoir dynamic pressure drop $\Delta P_{\mathrm{d}}$ is the dynamic pressure difference between reservoir inlet and outlet, which is therefore the relative dynamic pressure at reservoir inlet. Since the reservoir dynamic pressure drop $\Delta P_{\mathrm{d}}$ is directly related to geofluid circulating pumping work, so we use it as another comparison criterion to examine the effect of the six parameters.

In sum, we use the geofluid dimensionless outlet temperature $\tilde{T}_{\text {out }}$ and the reservoir dynamic pressure drop $\Delta P_{\mathrm{d}}$ as criteria to examine the effect of the six parameters.

Before the numerical computations, we use parameters of case $\mathrm{SC} 0$ to test the mesh convergence and time step convergence of the numerical model in COMSOL. The mesh scheme as shown in Fig. 6 has an error smaller than $10^{-6}$ in the energy and momentum balance of Eqs. (25), (27), and (30)-(32). Time steps are automatically chosen by COMSOL time-dependent solver that matches a tolerance of $10^{-6}$. The time step is $\sim 10^{-13}$ initially and gradually increases to $10^{-4}$.

3.4.1 Effect of Flow Direction. The effect of flow direction is analyzed by comparing cases $\mathrm{SC} 0$ and $\mathrm{SC} 1$.

Figures $7(c)$ and $7(d)$ show the dimensionless temperature profile $\tilde{T}_{\mathrm{r}}$ of the rock block and the relative dynamic pressure profile $\hat{P}_{\mathrm{d}}$ after 40 years of operation, using parameters listed as case SC0 in Table 6. Arrows show the dimensionless velocity of the geofluid. Initially, the dimensionless temperature of the rock block

Table 4 Assumptions of fixed parameters in reservoir performance analysis

\begin{tabular}{lccc}
\hline \hline Parameters & Symbol & Value & Unit \\
\hline Heat capacity of hot rocks & $c_{\mathrm{r}}$ & $794[28]$ & $\mathrm{J} / \mathrm{kg} \mathrm{K}$ \\
Thermal conductivity of hot rocks & $k_{\mathrm{r}}$ & $1.61[28]$ & $\mathrm{W} / \mathrm{m} \mathrm{K}$ \\
Density of hot rocks & $\rho_{\mathrm{r}}$ & $2700[28]$ & $\mathrm{kg} / \mathrm{m}^{3}$ \\
Thermal diffusivity of hot rocks & $\alpha_{\mathrm{r}}$ & $7.51 \times 10^{-7}$ & $\mathrm{~m}^{2} / \mathrm{s}$ \\
Total mass flow rate in reservoir & $\dot{m}$ & 105.5 & $\mathrm{~kg} / \mathrm{s}$ \\
Reservoir inflow geofluid temperature & $T_{\text {in }}$ & $70[29,30]$ & ${ }^{\circ} \mathrm{C}$ \\
Reservoir inflow geofluid density & $\rho_{\text {in }}$ & $977.8[31]$ & $\mathrm{kg} / \mathrm{m}^{3}$ \\
Reservoir geofluid inlet/outlet length & $L_{\text {in }} / L_{\text {out }}$ & $0.2 R$ & $\mathrm{~m}$ \\
Reservoir life time & Life & 40 & $\mathrm{yr}$ \\
\hline \hline
\end{tabular}

ranges from 0.9256 to 1.0744 (Fig. $7(a)$ ) due to the thermal gradient.

As shown in Fig. 7(c), the rock block's temperature drops significantly after 40 years of cold geofluid sweeping. Since cold geofluid enters at the bottom of fracture, the rock block bottom has the greatest temperature drop. The dynamic pressure difference $\Delta P_{\mathrm{d}}$ between geofluid inlet and outlet, shown in Fig. $7(d)$ is caused by friction and buoyancy. When the geofluid flows upward, buoyancy helps the flow.

If we reverse the geofluid flow direction to make it enter the fracture at the top and leave at the bottom, the dimensionless temperature profile $\tilde{T}_{\mathrm{r}}$ of the rock block and the relative dynamic pressure profile $\hat{P}_{\mathrm{d}}$ after 40 years of operation are shown in Figs. 7(e) and $7(f)$, using parameter values listed as case SC1 in Table 6. Since the cold geofluid enters from the top, the rock block has a lower temperature at the top.

The geofluid dimensionless outlet temperature $\tilde{T}_{\text {out }}$ as a function of operation time for upward and downward flows is shown in Fig. 8(a). The dimensionless geofluid outlet temperature $\tilde{T}_{\text {out }}$ drops to below 0.5 after 40 years. The temperature drawdown for downward flow is somewhat faster than upward flow for the initial $4 \mathrm{yr}$, even though the downward flow has a higher initial temperature because of the geothermal gradient, but the drawdown rate is nearly the same after the initial $4 \mathrm{yr}$. The reservoir dynamic pressure drops $\Delta P_{\mathrm{d}}$ are shown in Fig. $9(a)$ for the geofluid flowing upward and downward. When the geofluid flows upward, the dynamic pressure drop increases with operation time because the decrease of the geofluid temperature in a fracture reduces the flow-assisting buoyancy effect. When geofluid flows downward, the dynamic pressure drop decreases with operation time because the decrease of the geofluid temperature in a fracture reduces the flow-hindering buoyancy effect.

If we keep the geofluid temperature drawdown to a certain degree (for example, keep $\tilde{T}_{\text {out }}>0.9$, corresponding to first $5 \mathrm{yr}$ of operation, which ensures constant heat production rate of the reservoir) where the buoyancy is large, the upward flow scheme has less dynamic pressure drop within the reservoir, which is desirable.

In sum, the downward flow scheme has faster temperature drawdown at the beginning of operation and larger reservoir dynamic pressure drop, thus presenting worse reservoir performance, so the upward flow scheme is preferred.

3.4.2 Effect of Fracture Separation Distance $2 F_{\mathrm{s}}$. Figures $8(b)$ and $9(b)$ show the dimensionless outlet temperature $\tilde{T}_{\text {out }}$ and reservoir dynamic pressure drop $\Delta P_{\mathrm{d}}$ with respect to operation time, using the parameters listed as case SC2 in Table 6. The influence of $F_{\mathrm{s}}$ becomes negligible when $F_{\mathrm{s}}$ reaches a certain value (around $60 \mathrm{~m}$ ), which implies that the thermal penetration length in $y$ direction (of order $\sqrt{\alpha_{\mathrm{r}} \mathrm{Life}_{\mathrm{r}}} \approx 30.78 \mathrm{~m}$ [9]) is around $60 \mathrm{~m}$.

3.4.3 Effect of Fracture Radius $R$. Figures $8(c)$ and $9(c)$ show dimensionless outlet temperature $\tilde{T}_{\text {out }}$ and reservoir dynamic pressure drop $\Delta P_{\mathrm{d}}$ with respect to operation time, using the parameters listed as case SC3 in Table 6. As seen, increasing the fracture radius slows the geofluid outlet temperature $\tilde{T}_{\text {out }}$ drawdown because larger radii present a larger volume of hot rocks for releasing heat. Radii $R=750 \mathrm{~m}$ and $1000 \mathrm{~m}$ show nearly no thermal drawdown over 40 years.

As seen in Fig. 9(c), increasing the fracture radius $R$ lowers the dynamic reservoir pressure drop $\Delta P_{\mathrm{d}}$, which is because a larger fracture results in a higher geofluid outlet temperature that leads to higher flow-assisting buoyancy forces.

However, larger $R$ requires more energy to fracture, so there exists a value of $R$ that may be desirable from the energy balance standpoint. The following Sec. 3.4.6 describes the way to find it.

3.4.4 Effect of the Number of Fractures $N_{\mathrm{f}}$. Figures $8(d)$ and $9(d)$ show the dimensionless outlet temperature $\tilde{T}_{\text {out }}$ and reservoir dynamic pressure drop $\Delta P_{\mathrm{d}}$ with respect to operation time, using 
Table 5 Geofluid thermal properties in the nine cases studied for reservoir performance analysis

\begin{tabular}{|c|c|c|c|c|c|c|c|c|c|c|}
\hline \multirow{2}{*}{$\begin{array}{l}\text { Average reservoir depth }(\mathrm{km}) \\
\text { Thermal gradient }\left({ }^{\circ} \mathrm{C} / \mathrm{km}\right)\end{array}$} & \multirow{2}{*}{$\begin{array}{c}\bar{Z}_{\mathrm{r}} \\
\mathrm{Th}_{\mathrm{g}}\end{array}$} & \multicolumn{3}{|c|}{5} & \multicolumn{3}{|c|}{7.5} & \multicolumn{3}{|c|}{10} \\
\hline & & 40 & 60 & 80 & 40 & 60 & 80 & 40 & 60 & 80 \\
\hline Average reservoir temperature $\left({ }^{\circ} \mathrm{C}\right)$ & $\bar{T}_{\mathrm{r}, \infty}$ & 215 & 315 & 415 & 315 & 465 & 615 & 415 & 615 & 815 \\
\hline Average reservoir pressure $(\mathrm{MPa})$ & $\bar{P}_{\mathrm{r}}$ & 47.9 & 47.9 & 47.9 & 71.9 & 71.9 & 71.9 & 95.8 & 95.8 & 95.8 \\
\hline Average geofluid density $\left(\mathrm{kg} / \mathrm{m}^{3}\right)$ & $\rho$ & 947.9 & 903.2 & 849.6 & 916.3 & 838.8 & 740.1 & 881.6 & 767.7 & 617.9 \\
\hline Average geofluid viscocity $\left(10^{-4} \mathrm{~Pa} \cdot \mathrm{s}\right)$ & $\mu$ & 2.046 & 1.507 & 1.204 & 1.559 & 1.148 & 0.9136 & 1.301 & 0.9669 & 0.7512 \\
\hline Average Geofluid Volume expansion $\left(10^{-3}, 1 / \mathrm{K}\right)$ & $\beta_{\mathrm{T}}$ & 0.8573 & 1.083 & 1.377 & 1.003 & 1.379 & 2.029 & 1.129 & 1.693 & 2.755 \\
\hline Average geofluid specific heat $(\mathrm{kJ} / \mathrm{kg} \mathrm{K})$ & $c$ & 4.167 & 4.269 & 4.444 & 4.200 & 4.422 & 4.857 & 4.245 & 4.605 & 5.298 \\
\hline
\end{tabular}

the parameters listed as case SC4 in Table 6. Increasing the number of fractures indicates decreasing the mass flow rate $\dot{m}_{\mathrm{f}}$ in each fracture because $\dot{m}_{\mathrm{f}} \cdot N_{\mathrm{f}}=\dot{m}$, where the total mass flow rate in the reservoir, $\dot{m}$, is assumed to be constant (Table 4 ). $N_{\mathrm{f}}=15$ shows nearly no thermal drawdown.

If the reservoir design does not allow the dimensionless outlet temperature $\tilde{T}_{\text {out }}$ to drop below 0.9 over 40 years, then the minimal number of fractures is around $N_{\mathrm{f}}=15$ (Fig. $8(d)$ ), for $F_{\mathrm{s}}=60 \mathrm{~m}, R=500 \mathrm{~m}, \bar{w}=2 \mathrm{~mm}$, and $k_{\mathrm{f}}=10^{-13} \mathrm{~m}^{2}$.

As seen in Fig. $9(d)$, increasing the number of fractures $N_{\mathrm{f}}$ lowers the dynamic reservoir pressure drop $\Delta P_{\mathrm{d}}$, which is because a larger number of fractures result in a higher geofluid outlet temperature that leads to higher flow-assisting buoyancy forces.

In addition, larger number of fractures results in lower geofluid mass flow rate in each fracture $\dot{m}_{\mathrm{f}}$, which reduces the frictional pressure loss. Therefore, a large number of fractures is desirable from both thermal drawdown and reservoir pressure loss points of view. However, more fractures consume more fracturing energy, so there should be a recommended number of fractures. The way to find the recommended $N_{\mathrm{f}}$ is discussed in the following Sec. 3.4.6.

3.4.5 Effect of Fracture Width $\bar{w}$ and Permeability $k_{\mathrm{f}}$. Figures 8 , and $9(e), 9(f)$ show the dimensionless outlet temperature $\tilde{T}_{\text {out }}$ and reservoir dynamic pressure drop $\Delta P_{\mathrm{d}}$ with respect to operation time, using the parameters listed as case SC5 and case SC6 in Table 6 , respectively.

Figures $8(e)$ and $8(f)$ show that the reservoir dimensionless outlet geofluid temperature $\tilde{T}_{\text {out }}$ is insensitive to the fracture width $\bar{w}$ and permeability $k_{\mathrm{f}}$. Since the fracture width $\bar{w}$ and permeability $k_{\mathrm{f}}$ influence the governing equations by parameter $K_{2}$ and $K_{3}$ that are only in Eq. (31), the results thus indicate that the pressure field influenced by $K_{2}$ and $K_{3}$ has little influence on the temperature field. Further explanation is that since the result shows that $K_{2}$ and $K_{3}$ have little influence on the nondimensional velocity field, so they have little influence on $-\partial \tilde{T}_{\mathrm{r}} /\left.\partial \tilde{y}\right|_{\tilde{y}=0}$ given by Eq. (27).

Figures $9(e)$ and $9(f)$ show that the fracture width $\bar{w}$ and permeability $k_{\mathrm{f}}$ have a significant influence on the reservoir dynamic pressure drop: the dynamic pressure drop in the reservoir decreases as the fracture becomes wider and as the permeability becomes larger (approximately $\Delta P_{\mathrm{d}} \propto 1 / \bar{w} \cdot k_{\mathrm{f}}$ ), as expected. Therefore, we should aim to create wider and more permeable fractures. From Fig. 4(b), we see that the average width of a fracture is around $2 \mathrm{~mm}$, so we choose $\bar{w}=2 \mathrm{~mm}$. References [13],
[20], and [25-27] suggest an average permeability of $10^{-13} \mathrm{~m}^{2}$ for fractured reservoirs, so we choose $k_{\mathrm{f}}=10^{-13} \mathrm{~m}^{2}$. Clearly, fracturing methods that could produce wider fracture or increase the fracture permeability could be adapted in practice to reduce reservoir dynamic pressure drop $\Delta P_{\mathrm{d}}$.

3.4.6 Recommended Design of Reservoir. An EGS reservoir will be abandoned when its thermal drawdown reaches certain degree. In this work, we aim to design a reservoir to achieve $\tilde{T}_{\text {out }} \geq 0.9$ (thermal drawdown $\leq 10 \%$ ) over 40 years of operation.

The design of an EGS reservoir should aim at finding the minimal number of fractures that could satisfy $\leq 10 \%$ thermal drawdown over 40 years to save fracturing energy, which is proportional to the number of fracture. So there exists a minimal number of fractures $N_{\mathrm{f} \text {,min }}$ that satisfies $\tilde{T}_{\text {out }}=0.9$ after 40 years for given $F_{\mathrm{s}}, R, \bar{w}$, and $k_{\mathrm{f}}$. For example, $N_{\mathrm{f}, \min }=15$ for $F_{\mathrm{s}}=60 \mathrm{~m}$, $R=500 \mathrm{~m}, \bar{w}=2 \mathrm{~mm}$, and $k_{\mathrm{f}}=10^{-13} \mathrm{~m}^{2}$ as shown in Fig. $8(d)$.

If $N_{\mathrm{f}}>N_{\mathrm{f}, \min }, \tilde{T}_{\text {out }}$ will be greater than 0.9 after 40 years. Since the mass flow rate $\dot{m}_{\mathrm{f}}$ in each fracture is inversely proportional to $N_{\mathrm{f}}$, the $N_{\mathrm{f}, \text { min }}$ also indicates the maximal allowed geofluid mass flow rate in each fracture to keep the thermal drawdown rate below $10 \%$ over 40 years.

For geofluid flows upward, $F_{\mathrm{s}}=60 \mathrm{~m}, \bar{w}=2 \mathrm{~mm}$, and $k_{\mathrm{f}}=10^{-13} \mathrm{~m}^{2}$, Fig. 10 plots $N_{\mathrm{f} \text {,min }}$ with respect to fracture radius $R$. Each $N_{\text {f,min }}$ is found by solving Eqs. (25)-(34). We could get the following expression from data regression:

$$
N_{\mathrm{f}, \min }=13.9 \times 10^{5} R^{-1.85}
$$

Because of the thermal gradient, for upward flow scheme, geofluid leaves the reservoir at top where temperature is lower than the average reservoir temperature (Fig. 7(a)). Then for larger fracture radii $R$, we get lower initial dimensionless geofluid outlet temperature $\tilde{T}_{\text {out }}$ (Fig. 8(a)).

To make $\tilde{T}_{\text {out }} \geq 0.9$ initially, there is an upper bound of fracture radius $R_{\max }$

$$
1-\frac{\sqrt{R_{\max }^{2}-L_{\text {out }}^{2}} \cdot \mathrm{Th}_{\mathrm{g}}}{\left(\bar{T}_{\mathrm{r}, \infty}-T_{\text {in }}\right)}=0.9 \rightarrow R_{\max }=\frac{\bar{T}_{\mathrm{r}, \infty}-T_{\text {in }}}{9.8 \mathrm{Th}_{\mathrm{g}}}
$$

where the thermal gradient $\mathrm{Th}_{\mathrm{g}}$ is in units of ${ }^{\circ} \mathrm{C} / \mathrm{m}$.

As seen in Figs. 8(c) and $9(c)$, larger $R$ is desirable because they reduce both the thermal drawdown and the reservoir dynamic

\begin{tabular}{|c|c|c|c|c|c|c|c|}
\hline Case & $\begin{array}{c}\text { Flow } \\
\text { direction }\end{array}$ & $\begin{array}{c}\text { Half fracture } \\
\text { separation distance } F_{\mathrm{s}}(\mathrm{m})\end{array}$ & $\begin{array}{l}\text { Fracture radius } \\
R(\times 100 \mathrm{~m})\end{array}$ & $\begin{array}{l}\text { s Number of } \\
\text { fractures } N_{\mathrm{f}} \text { v }\end{array}$ & $\begin{array}{c}\text { Fracture } \\
\text { width } \bar{w}(\mathrm{~mm})\end{array}$ & $\begin{array}{c}\text { Fracture } \\
\text { ) permeability } k_{\mathrm{f}}\left(10^{-13} \mathrm{~m}^{2}\right)\end{array}$ & $\begin{array}{l}\text { Results } \\
\text { shown in }\end{array}$ \\
\hline $\mathrm{SC} 0$ & Upward & 60 & 5 & 5 & 2 & 1 & Figure $7(c), 7(d)$, Fig. $8(a)$, and Fig. $9(a)$ \\
\hline $\mathrm{SC} 1$ & Downward & 60 & 5 & 5 & 2 & 1 & Figure $7(e), 7(f)$, Fig. $8(a)$, and Fig. $9(a)$ \\
\hline $\mathrm{SC} 2$ & Upward & $30,60,90,120$ & 5 & 5 & 2 & 1 & Figures $8(b)$ and $9(b)$ \\
\hline $\mathrm{SC} 3$ & Upward & 60 & $2.5,5,7.5,10$ & 5 & 2 & 1 & Figures $8(c)$ and $9(c)$ \\
\hline $\mathrm{SC} 4$ & Upward & 60 & 5 & $1,5,10,15$ & 2 & 1 & Figures $8(d)$ and $9(d)$ \\
\hline SC5 & Upward & 60 & 5 & 5 & $1,2,4$ & 1 & Figures $8(e)$ and $9(e)$ \\
\hline SC6 & Upward & 60 & 5 & 5 & 2 & $0.1,1,10$ & Figures $8(f)$ and $9(f)$ \\
\hline
\end{tabular}

Table 6 Summary of parameter effects analysis 
(a)

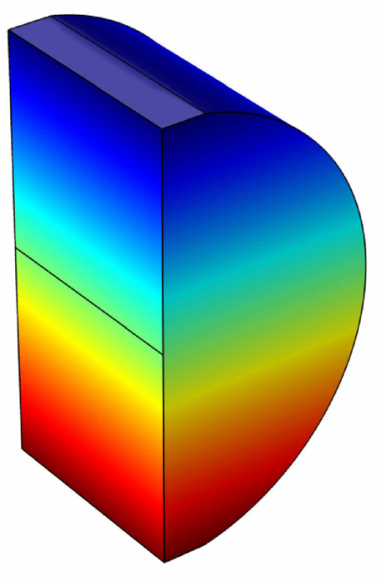

(c)

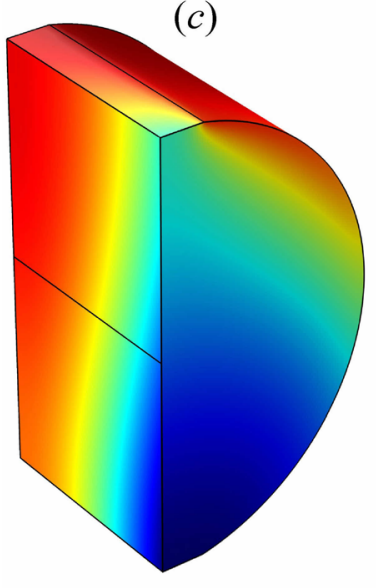

(e)

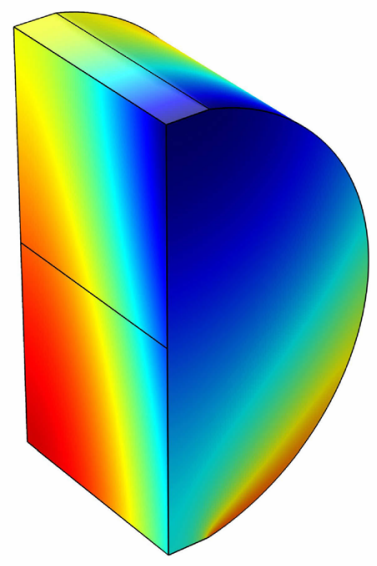

$\Delta 1.0744$

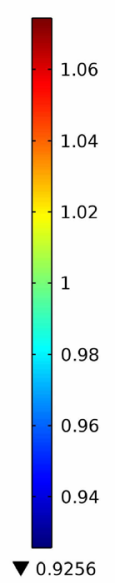

$\Delta 0.9371$

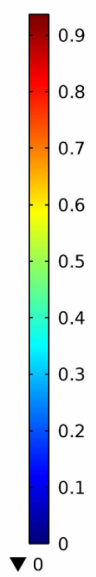

$\Delta 1.0197$

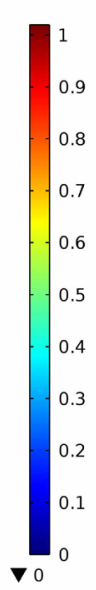

(b)

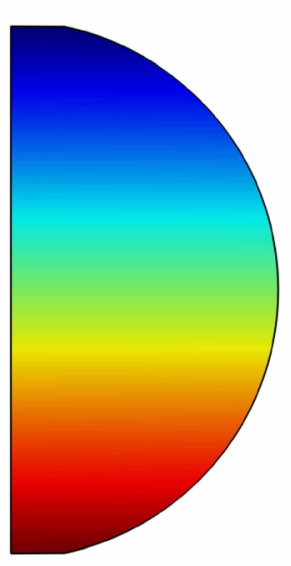

$\Delta 6.0607 \times 10^{-3}$

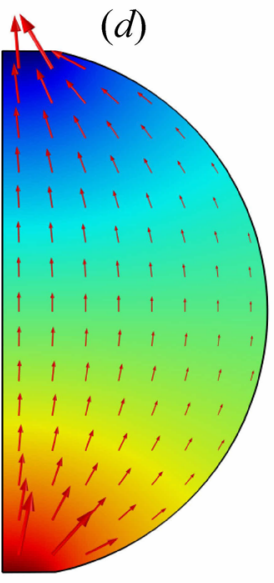

$\Delta 24.81$

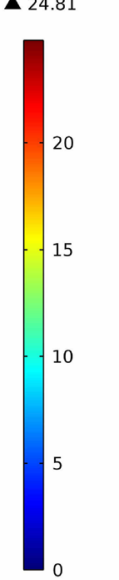

$(f)$

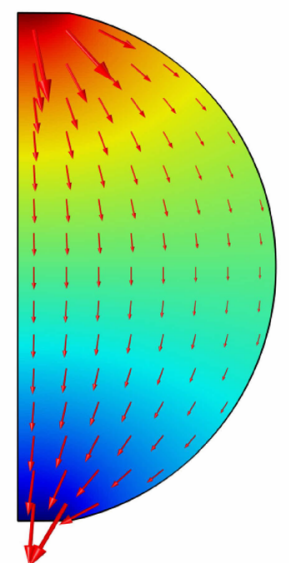

$\Delta 22.88$

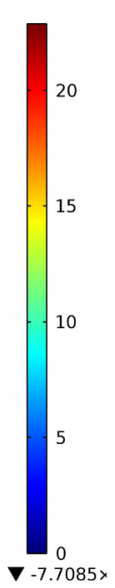

Fig. 7 (a), (c), and (e): The rock dimensionless temperature $\tilde{T}_{\mathrm{r}}$ field; Dimensionally, $\tilde{T}_{r}=0$ corresponds to $T_{r}=70^{\circ} \mathrm{C}$ and $\tilde{T}_{r}=1$ to $465^{\circ} \mathrm{C}$. (b), (d), (f): The rock relative dynamic pressure field $\hat{P}_{d}(\mathrm{GPa})$, The arrows in $(d)$ and $(f)$ show the fluid dimensionless velocity vectors. $V=1$ (at the geofluid inlet) corresponds to a dimensional velocity value of $V=5.37 \mathrm{~cm} / \mathrm{s}$, and $\tilde{V}=0$ to $V=0 \mathrm{~cm} / \mathrm{s}$. (a) and (b): At start of operation, (c) and (d): after 40 years of operation, Case SC0. $(e)$ and $(f)$ : after 40 years of operation, Case SC1.

pressure drop $\Delta P_{\mathrm{d}}$, but $R$ cannot exceed its maximal value defined by Eq. (38).

The fracturing energy needed for a single fracture is given by Eq. (12). Adding Eq. (12) to the energy needed for drilling the fracturing fluid supply wellbore, the total fracturing energy to create $N_{\mathrm{f}}$ fractures is

$$
W_{\mathrm{rsv}}=W_{\mathrm{hf}} \cdot N_{\mathrm{f}}+W_{\mathrm{h}-\text { hole }}=W_{\mathrm{hf}} \cdot N_{\mathrm{f}}+2 w_{\mathrm{h}-\mathrm{hole}} F_{\mathrm{s}} \cdot N_{\mathrm{f}}
$$

where $W_{\mathrm{h} \text {-hole }}$ is the energy consumption to drill a horizontal uncased fracturing wellbore (Fig. 5), which carries fracturing fluid to each fracturing location during the hydrofracturing process. $w_{\mathrm{h} \text {-hole }}$ is the energy consumption per meter of the horizontal 
(a)

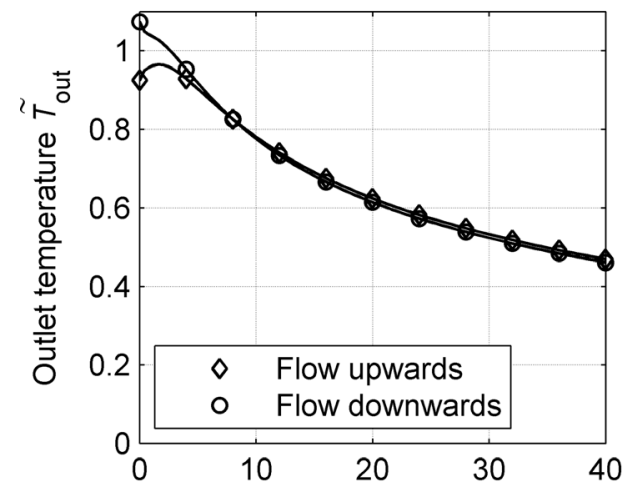

(c)

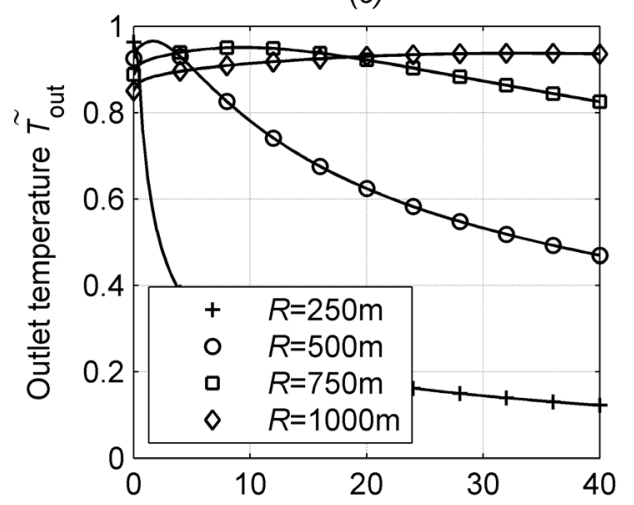

(e)

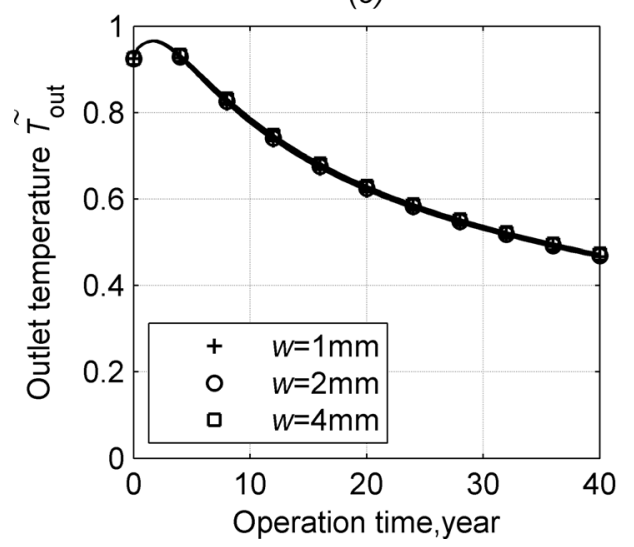

(b)

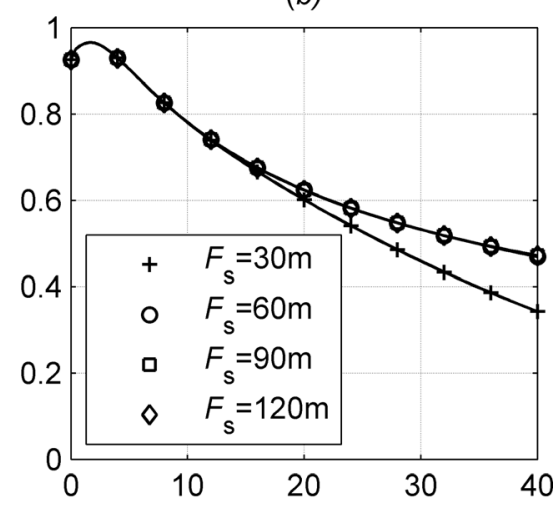

(d)

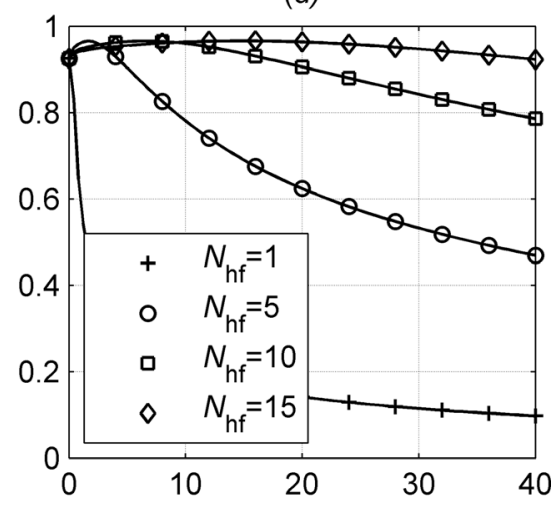

(f)

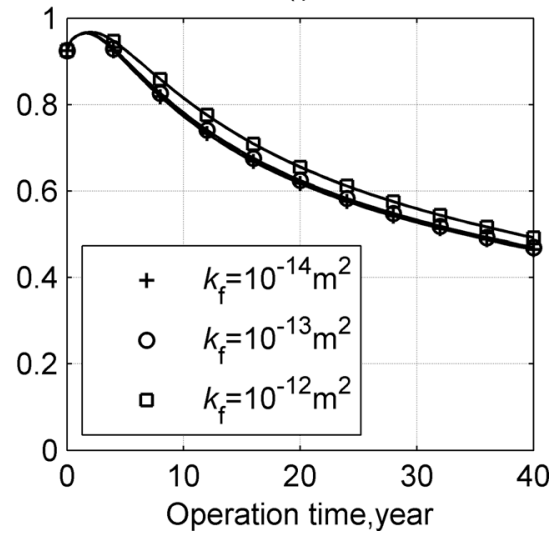

Fig. 8 Geofluid dimensionless outlet temperature $\tilde{T}_{\text {out }}$ as a function of operation time: case SC0 and SC1 (a), case SC2 (b), case SC3 (c), case SC4 (d), case SC5 (e), and case SC6 ( $f$ )

wellbore. The factor " 2 " is because the distance between fractures is $2 F_{\mathrm{s}}$. From the result presented in Sec. 2.2.2 of Ref. [29], we have $w_{\mathrm{h} \text {-hole }}=1.40 \times 10^{-2} \mathrm{TJ} / \mathrm{m}$ of an $8-1 / 2$ in. wellbore.

Then, combining Eqs. (12), (37), and (39), we have

$$
W_{\mathrm{rsv}}=1391682.18 R^{-1.85}\left(K_{\mathrm{hf}} \pi R^{2} \bar{w}+1.679\right)
$$

when $F_{\mathrm{s}}=60 \mathrm{~m}, \quad \bar{w}=2 \mathrm{~mm}, \quad$ and $k_{\mathrm{f}}=10^{-13} \mathrm{~m}^{2} \quad$ and $K_{\mathrm{hf}}=7.5672 \times 10^{-5}$ (Table 3), Fig. 11 plots $W_{\text {rsv }}$ with respect to $R$ according to Eq. (40). The minimal $W_{\mathrm{rsv}}$ appears at fracture radius $R=R_{\max }$. So the recommended radius of a fracture is $R_{\max }$. The corresponding minimal number of fractures $N_{\mathrm{f} \text {,min }}$ could be found by solving Eqs. (25)-(34) when $R=R_{\max }$.
In conclusion, a recommended design of a reservoir is to create $N_{\mathrm{f}}=N_{\mathrm{f}, \text { min }}$ fractures when each fracture has a radius $R=R_{\max }$. Then, the energy consumption of creating a reservoir that satisfies $\leq 10 \%$ thermal drawdown over 40 years will be the least (Eq. (40)).

3.5 Results and Discussion. The analysis results of EGS reservoirs listed in Table 1, which satisfy thermal drawdown of $\leq 10 \%$ over 40 years, are presented in Table 7 for $F_{\mathrm{s}}=60 \mathrm{~m}$, $\bar{w}=2 \mathrm{~mm}, k_{\mathrm{f}}=10^{-13} \mathrm{~m}^{2}$, and upward flows.

A recommended fracture radius $R_{\max }$ is determined by Eq. (38). Substitute $\bar{T}_{\mathrm{r}, \infty}$ in Eq. (38) with Eq. (1), we have 
(a)

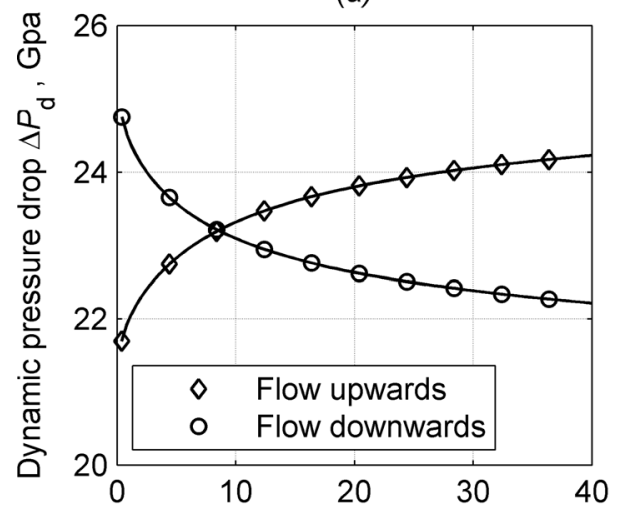

(c)

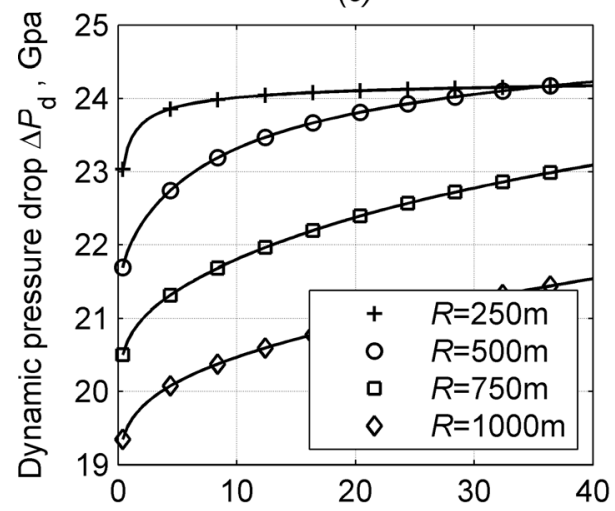

(e)

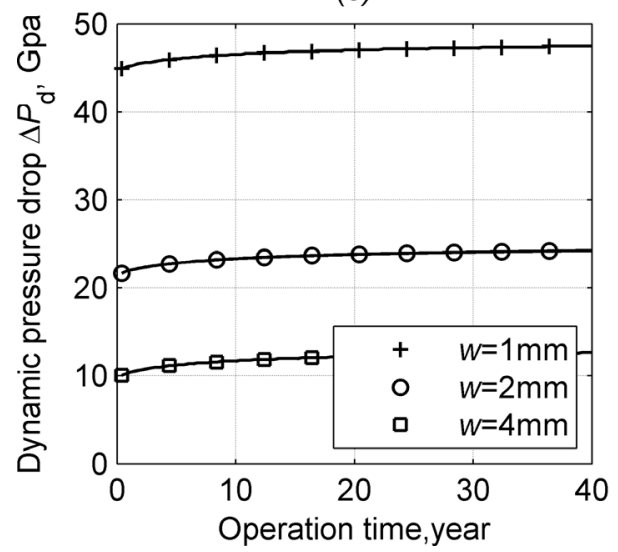

(b)

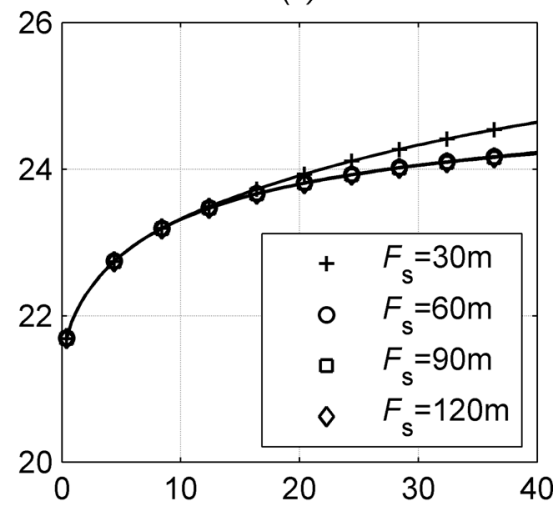

(d)

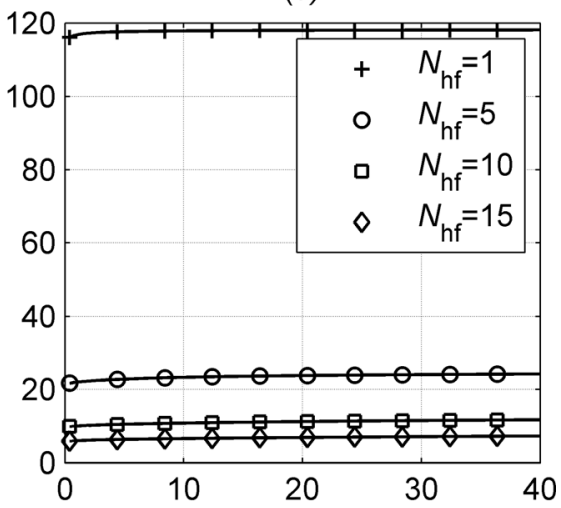

(f)

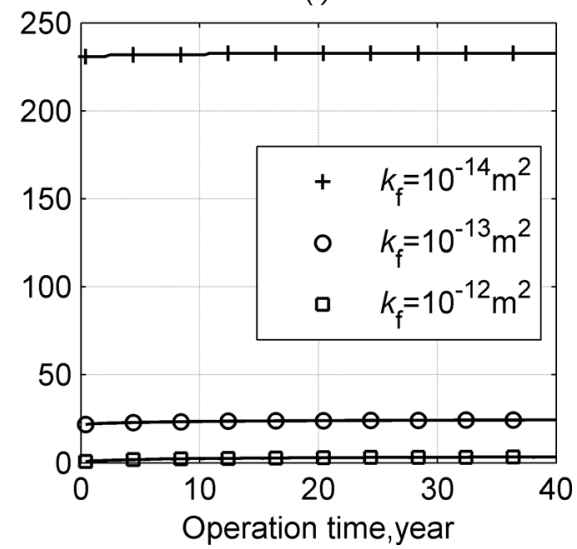

Fig. 9 Geofluid dynamic pressure drop in reservoir $\Delta P_{\mathrm{d}}(\mathrm{GPa})$ as a function of operation time: case SC0 and SC1 (a), case SC2 (b), case SC3 (c), case SC4 (d), case SC5 (e), and case $\operatorname{sc6}(f)$

$$
R_{\max }=\frac{15+\bar{Z}_{\mathrm{r}} \cdot \mathrm{Th}_{\mathrm{g}}-T_{\mathrm{in}}}{9.8 \mathrm{Th}_{\mathrm{g}}}=\frac{\bar{Z}_{\mathrm{r}}}{9.8}-\frac{T_{\mathrm{in}}-15}{9.8 \mathrm{Th}_{\mathrm{g}}}
$$

indicating that $R_{\max }$ increases with $\bar{Z}_{\mathrm{r}}$ and $\mathrm{Th}_{\mathrm{g}}$, which also can be seen in Table 7. The recommended number of fractures $N_{\mathrm{f}, \mathrm{min}}$ is found by solving Eqs. (25)-(34) when $R=R_{\max }$ for a reservoir that satisfies $\leq 10 \%$ thermal drawdown over 40 years. Table 7 shows that $N_{\mathrm{f} \text {,min }}$ decreases as $\bar{Z}_{\mathrm{r}}$ and $\mathrm{Th}_{\mathrm{g}}$ are increased. For hotter reservoirs, fewer fractures with larger radius are recommended to save fracturing energy.
The total pressure drop in the reservoir $\Delta P_{\mathrm{r}}$ is the sum of the dynamic pressure drop $\Delta P_{\mathrm{d}}$ and gravity

$$
\Delta P_{\mathrm{r}}=\Delta P_{\mathrm{d}}+\bar{\rho} g R_{\max }\left(\tilde{z}_{\text {in }}-\tilde{z}_{\text {out }}\right)
$$

Table 7 lists the total pressure drop $\Delta P_{\mathrm{r}}$ after 40 years of operation in a reservoir with $R=R_{\max }$ and $N_{\mathrm{f}}=N_{\mathrm{f} \text {,min }}$. We need to provide $\Delta P_{\mathrm{r}}$ at reservoir inlet to overcome geofluid friction and gravity when flow upward. For a given reservoir depth $\bar{Z}_{\mathrm{r}}, \Delta P_{\mathrm{r}}$ decreases with increased thermal gradient $T h_{\mathrm{g}}$ because of the higher flowassisting buoyancy effect. For given reservoir thermal gradient 


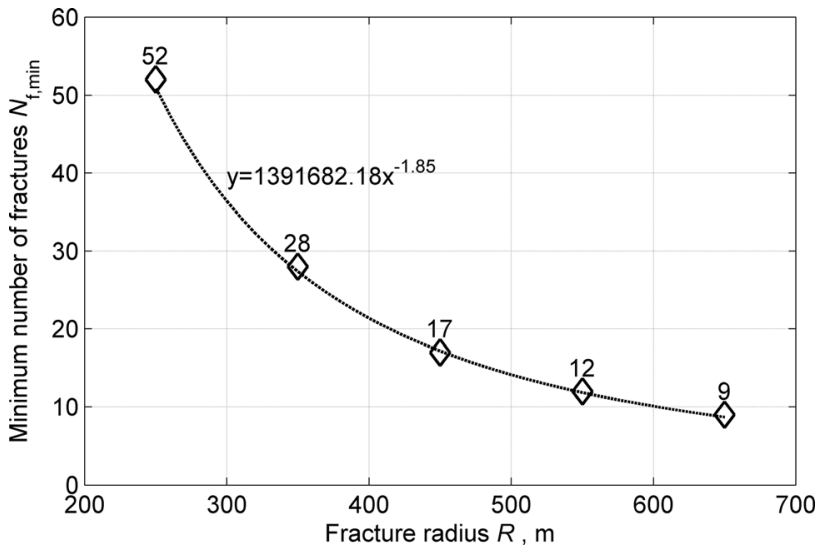

Fig. 10 Minimal number of fractures (for $10 \%$ drawdown in $40 \mathrm{yr}$ ) as a function of fracture radius $R ; F_{\mathrm{s}}=60 \mathrm{~m}, \bar{w}=2 \mathrm{~mm}$, $k_{\mathrm{f}}=10^{-13} \mathrm{~m}^{2}$, flow upward

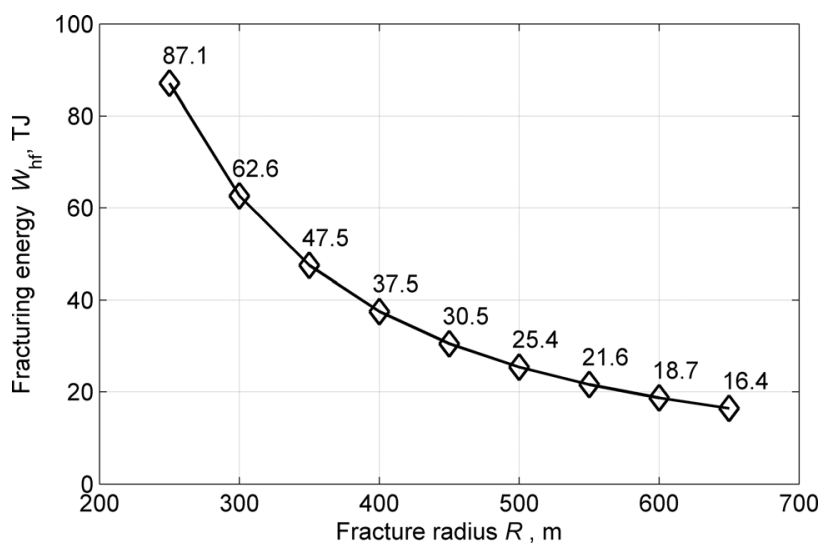

Fig. 11 The relation of fracturing energy cost $W_{\text {rsv }}$ with respect to fracture radius $R ; F=60 \mathrm{~m}, N_{\mathrm{f}}=N_{\mathrm{f}, \min } \bar{W}=2 \mathrm{~mm}$, $k_{\mathrm{f}}=10^{-13} \mathrm{~m}^{2}$, flow upward

Th $h_{\mathrm{g}}, \Delta P_{\mathrm{r}}$ increases with increased $\bar{Z}_{\mathrm{r}}$ because of substantially large $R_{\text {max }}$ in Eq. (42).

The energy needed for fracturing, $W_{\text {rsv }}$, is calculated by using Eqs. (12) and (39), as

$$
W_{\mathrm{rsv}}=N_{\mathrm{f}, \min }\left(K_{\mathrm{hf}} \pi R_{\max }^{2} \bar{w}+2 w_{\mathrm{h}-\mathrm{hole}} F_{\mathrm{s}}\right)
$$

Table 7 lists the fracturing energy $W_{\text {rsv }}$ calculated by Eq. (43), which decreases with increasing depth $\bar{Z}_{\mathrm{r}}$ and thermal gradients Th. $\mathrm{g}$. This is because $W_{\mathrm{rsv}}$ is proportional to $N_{\mathrm{f}, \mathrm{min}}$, which also decreases with increasing $\bar{Z}_{\mathrm{r}}$ and $\mathrm{Th}_{\mathrm{g}}$.

The number of years needed for the geothermal field energy output to compensate for the energy needed for the reservoir creation is defined by

$$
Y_{\mathrm{rsv}}=\frac{W_{\mathrm{rsv}}}{\dot{Q}_{\mathrm{r}} \cdot \eta_{\mathrm{p}} \cdot \eta_{\mathrm{c}} \cdot 31.536 \times 10^{6} \mathrm{~s} / \mathrm{yr}}
$$

where $\dot{Q}_{\mathrm{r}}$ is calculated by Eq. (35), $\eta_{\mathrm{c}}$ is the energy efficiency of power plants to convert heat to power. We take $\eta_{\mathrm{c}}=16 \%$ which is the national electricity generation efficiency by geothermal energy [32]. The fracturing pump efficiency, $\eta_{\mathrm{p}}$, is assumed to be $80 \%$. Table 7 lists the energy payback year of fracturing the reservoir for reservoir inlet temperature $T_{\mathrm{in}}=70^{\circ} \mathrm{C}[29,30]$, showing that the energy could be paid back within 3 months of operation and this time decreases as increased $\bar{Z}_{\mathrm{r}}$ and $\mathrm{Th}_{\mathrm{g}}$.

\section{Conclusions}

The work presents a mathematic model for calculating the energy consumption of the hydraulic fracturing process, focused on EGS reservoir creation. In a separate model, we compute the geofluid flow and heat transfer in the fractures. The results from these models for EGS reservoirs of depths of 5-10 km and thermal gradients of $40-80^{\circ} \mathrm{C} / \mathrm{km}$ are presented. The main contribution of this work is to examine quantitatively the energy input and output for a typical EGS reservoir by extending prior analyses from $5 \mathrm{~km}$ to $10 \mathrm{~km}$, improving and expanding existing models for flow and heat transfer in enhanced reservoirs to include buoyancy effects, and consideration of both upward and downward flows in them, and for the first time developing a simplified model for reservoir hydraulic fracturing energy consumption from which we present values of that energy.

The energy needed to create a fracture, $W_{\mathrm{hf}}$, is found to be proportional to the volume of the fracture $V_{\mathrm{hf}}$, where the proportionality coefficient between them, $K_{\mathrm{hf}}$, increases with reservoir depth $\bar{Z}_{\mathrm{r}}$, mostly because a larger in situ stress must be overcome to create fractures in deeper reservoir.

From the analysis of reservoir parameters (geofluid flow direction, fracture separation distance $2 F_{\mathrm{s}}$, fracture radius $R$, number of fractures $N_{\mathrm{f}}$, fracture width $\bar{w}$, and fracture permeability $k_{\mathrm{f}}$ ), we find:

(1) Geofluid flow upward is preferred than geofluid flow downward because buoyancy could help the flow.

(2) Increasing the fracture separation distance $2 F_{\mathrm{S}}$ slows down the thermal drawdown when $F_{\mathrm{s}}<60 \mathrm{~m}$. When $F_{\mathrm{s}}$ exceeds $60 \mathrm{~m}$, the thermal drawdown is no longer affected by $F_{\mathrm{s}}$, indicating that the thermal penetration length of cold geofluid sweep of hot rock blocks is about $60 \mathrm{~m}$. In practice, it thus may be desirable to separate the fractures by $120 \mathrm{~m}$ to avoid interaction between two fractures.

(3) The larger the fracture radius $R$, the slower is the thermal drawdown because larger volume of hot rocks is been swept.

(4) For a given geofluid total inflow rate, a larger number of fractures $N_{\mathrm{f}}$ result obviously in a smaller mass flow rate $\dot{m}_{\mathrm{f}}$ in each fracture, which reduces the thermal drawdown rate.

(5) The fracture average width $\bar{w}$ and permeability $k_{\mathrm{f}}$ have negligible effect on the heat transfer from hot rock blocks to the geofluid in the fractures. Their effect on geofluid dynamic pressure drop $\Delta P_{\mathrm{d}}$ in the reservoir is, however, significant, where $\Delta P_{\mathrm{d}} \propto 1 / \bar{w} \cdot k_{\mathrm{f}}$ approximately. In

\begin{tabular}{|c|c|c|c|c|c|c|c|c|c|c|}
\hline \multirow{2}{*}{$\begin{array}{l}\text { Average reservoir depth }(\mathrm{km}) \\
\text { Thermal gradient }\left({ }^{\circ} \mathrm{C} / \mathrm{km}\right)\end{array}$} & \multirow{2}{*}{$\frac{\bar{Z}_{\mathrm{r}}}{\mathrm{Th}_{\mathrm{g}}}$} & \multicolumn{3}{|c|}{5} & \multicolumn{3}{|c|}{7.5} & \multicolumn{3}{|c|}{10} \\
\hline & & 40 & 60 & 80 & 40 & 60 & 80 & 40 & 60 & 80 \\
\hline Recommended fracture radius (m) & $R_{\max }$ & 363 & 408 & 431 & 613 & 658 & 681 & 863 & 908 & 931 \\
\hline Recommended number of fractures & $N_{\mathrm{f}, \min }$ & 30 & 23 & 19 & 10 & 8 & 7 & 5 & 4 & 4 \\
\hline Reservoir pressure drop (GPa) & $\Delta P_{\mathrm{r}}$ & 20.2 & 20.8 & 20.4 & 37.5 & 35.7 & 32.1 & 55.7 & 50.9 & 38.8 \\
\hline Fracturing energy $(\mathrm{TJ})$ & $W_{\mathrm{rsv}}$ & 51.7 & 39.9 & 33.1 & 18.6 & 15.1 & 13.3 & 10.7 & 8.8 & 8.9 \\
\hline Energy payback year (yr) & $Y_{\mathrm{rsv}}$ & 0.235 & 0.105 & 0.059 & 0.050 & 0.024 & 0.014 & 0.020 & 0.010 & 0.006 \\
\hline
\end{tabular}

Table 7 Recommended design of reservoirs for different reservoir depths and average thermal gradient 
practice, the achievable value for $\bar{w}$ and $k_{\mathrm{f}}$ is $\bar{w}=2 \mathrm{~mm}$ and $k_{\mathrm{f}}=10^{-13} \mathrm{~m}^{2}$.

(6) For a given reservoir, to satisfy thermal drawdown $\leq 10 \%$ over 40 years, the analysis recommends that each fracture should have radius $R=R_{\max }$ (Eq. (41)) and the corresponding minimal number of needed fracture $N_{\mathrm{f}, \min }$ can be found by solving the nonlinear model.

After this parametric analysis, we calculated the recommended radius of fracture $R_{\max }$, recommended number of fractures $N_{\mathrm{f}, \mathrm{min}}$, reservoir pressure drop $\Delta P_{\mathrm{r}}$, fracturing energy consumption $W_{\mathrm{rsv}}$ and energy payback year $Y_{\text {rsv }}$ for nine different reservoirs and tabulated the results in Table 7. $R_{\max }$ increases with increased $\bar{Z}_{\mathrm{r}}$ and $\mathrm{Th}_{\mathrm{g}}$ while $N_{\mathrm{f}, \mathrm{min}}, \Delta P_{\mathrm{r}}, W_{\mathrm{rsv}}$, and $Y_{\mathrm{rsv}}$ decreases with increased $\bar{Z}_{\mathrm{r}}$ and $\mathrm{Th}_{\mathrm{g}}$. Deeper reservoirs with higher thermal gradient will require less pressure to drive the geofluid circulation in the reservoir and require fewer fractures, which reduces the energy consumption for creating the reservoir. The energy payback of the EGS reservoir is found to be less than 3 months.

\section{Nomenclature}

$c=$ average geofluid specific heat in reservoir $(\mathrm{J} / \mathrm{kg} \mathrm{K})$

$c_{\mathrm{r}}=$ heat capacity of surrounding rocks $(\mathrm{J} / \mathrm{kg} \mathrm{K})$

$E=$ Young's modulus of rock material $(\mathrm{Pa})$

$F_{\mathrm{s}}=$ the half distance between fractures (m)

$g=$ gravitational acceleration $\left(9.8 \mathrm{~m} / \mathrm{s}^{2}\right)$

$G=$ shear modulus of rock $(\mathrm{Pa})$

$H=$ height of rectangular fracture $(\mathrm{m})$

$k_{\mathrm{f}}=$ fracture permeability $\left(\mathrm{m}^{2}\right)$

$k_{\mathrm{r}}=$ thermal conductivity of surrounding rocks $(\mathrm{W} / \mathrm{m} \mathrm{K})$

$K_{\mathrm{hf}}=$ correlation coefficient of hydro-fracturing pumping energy consumption with fracture volume $\left(\mathrm{TJ} / \mathrm{m}^{3}\right)$

$L=$ length of rectangular fracture $(\mathrm{m})$

$L_{\text {in }} / L_{\text {out }}=$ geofluid inlet/outlet length in a fracture (m)

Life $_{\mathrm{r}}=$ the required reservoir life time (yr)

$\dot{m}=$ total geofluid mass flow rate in reservoir $(\mathrm{kg} / \mathrm{s})$

$\dot{m}_{\mathrm{f}}=$ mass flow rate of geofluid in each fracture $(\mathrm{kg} / \mathrm{s})$

$N_{\mathrm{f}}=$ number of fractures in a reservoir

$P=$ geofluid pressure in reservoir $(\mathrm{Pa})$

$P^{*}=$ a characteristic pressure related to Darcy's velocity $\operatorname{drag}(\mathrm{Pa})$

$\hat{P}_{\mathrm{d}}=$ relative dynamic pressure of geofluid (MPa)

$\bar{P}_{\mathrm{r}}=$ average reservoir pressure $(\mathrm{Pa})$

$P_{\mathrm{hf}}=$ the pressure applied in situ to fracture rocks $(\mathrm{Pa})$

$P_{\text {out }}=$ geofluid pressure at reservoir outlet $(\mathrm{Pa})$

$P_{\mathrm{r}, \mathrm{hp}}=$ the hydrostatic pressure at reservoir depth $(\mathrm{Pa})$

$P_{\text {ref }}=$ reference pressure of geofluid to evaluate property $(\mathrm{Pa})$

$\dot{q}=$ heat flux from rock/geofluid interface into geofluid in fracture $\left(\mathrm{W} / \mathrm{m}^{2}\right)$

$\dot{Q}_{\mathrm{r}}=$ the heat production rate of the reservoir $(\mathrm{W})$

$\dot{q}_{\mathrm{hf}}=$ volumetric flow rate of fracturing fluid $\left(\mathrm{m}^{3} / \mathrm{s}\right)$

$R=$ radius of cylindrical shape fracture $(\mathrm{m})$

$r_{\mathrm{iw}}=$ radius of injection wellbore $(\mathrm{m})$

$\mathrm{Re}=$ Reynolds number

$S_{\mathrm{H}}=$ the in situ horizontal compressive stress $(\mathrm{Pa})$

$S_{\mathrm{L}}=$ the in situ vertical compressive stress $(\mathrm{Pa})$

$S_{\mathrm{t}}=$ effective tensile breaking strength of the rock $(\mathrm{Pa})$

$t=$ reservoir operation time (s)

$T=$ geofluid temperature in reservoir $(\mathrm{K})$

$t_{\mathrm{hf}}=$ hydraulic fracturing treatment time $(\mathrm{s})$

$T_{\mathrm{r}}=$ reservoir rock temperature $(\mathrm{K})$

$T_{\mathrm{r}, \infty}=$ the temperature of undisturbed reservoir rock $(\mathrm{K})$

$T_{\text {in }} / T_{\text {out }}=$ reservoir inlet/outlet geofluid temperature $(\mathrm{K})$

$T_{\text {ref }}=$ reference temperature of geofluid to evaluate property (K)

$\bar{T}_{\mathrm{r}, \infty}=$ average temperature of reservoir $(\mathrm{K})$

$\mathrm{Th}_{\mathrm{g}}=$ the average geothermal gradient $\left({ }^{\circ} \mathrm{C} / \mathrm{km}\right)$

$U=$ geofluid velocity in $x$ direction $(\mathrm{m} / \mathrm{s})$

$V_{\mathrm{r}}=$ fracturing fluid velocity $(\mathrm{m} / \mathrm{s})$
$V=$ geofluid velocity in $z$ direction $(\mathrm{m} / \mathrm{s})$

$V^{*}=$ inflow velocity in each fracture $(\mathrm{m} / \mathrm{s})$

$V_{\mathrm{hf}}=$ volume of fracture $\left(\mathrm{m}^{3}\right)$

$w=$ fracture width $(\mathrm{m})$

$\bar{w}=$ average fracture width $(\mathrm{m})$

$W_{\mathrm{hf}}=$ energy consumption of hydraulic fracturing (TJ)

$w_{\mathrm{h} \text {-hole }}=$ energy consumption per meter of the horizontal wellbore $(\mathrm{TJ} / \mathrm{m})$

$W_{\text {h-hole }}=$ energy consumption to drill horizontal uncased wellbore used in fracturing process (TJ)

$W_{\text {rsv }}=$ overall fracturing energy consumption $(\mathrm{TJ})$

$x=$ length in $x$ direction $(\mathrm{m})$

$y=$ length in $y$ direction $(\mathrm{m})$

$z=$ length in $z$ direction $(\mathrm{m})$

$\bar{Z}_{\mathrm{r}}=$ average reservoir depth $(\mathrm{m})$

$\alpha=$ average geofluid thermal diffusivity in reservoir $\left(\mathrm{m}^{2} / \mathrm{s}\right)$

$\alpha_{\mathrm{r}}=$ thermal diffusivity of rocks $\left(\mathrm{m}^{2} / \mathrm{s}\right)$

$\beta_{\mathrm{T}}=$ average geofluid thermal expansion coefficient in reservoir $\left(\mathrm{K}^{-1}\right)$

$\Delta P_{\mathrm{r}}=$ pressure drop in reservoir $(\mathrm{MPa})$

$\Delta P_{\mathrm{d}}=$ reservoir dynamic pressure drop $(\mathrm{MPa})$

$\Delta P_{\mathrm{IW}}=$ the friction pressure loss when fracturing fluid flow through injection well $(\mathrm{Pa})$

$\eta_{\mathrm{c}}=$ energy efficiency of power plants to convert heat into power $(\%)$

$\eta_{\mathrm{p}}=$ hydrofracturing pump efficiency $(\%)$

$\mu=$ average geofluid viscosity in reservoir $(\mathrm{Pa} \cdot \mathrm{s})$

$\mu_{\mathrm{hf}}=$ viscosity of fracturing fluid (Pa.s)

$\nu=$ Poisson's ratio of rock material

$\rho=$ average geofluid density in reservoir $\left(\mathrm{kg} / \mathrm{m}^{3}\right)$

$\rho_{\mathrm{r}}=$ density of surrounding rocks $\left(\mathrm{kg} / \mathrm{m}^{3}\right)$

$\rho_{\text {in }}=$ geofluid density at reservoir inlet $\left(\mathrm{kg} / \mathrm{m}^{3}\right)$

$\sigma_{\mathrm{H}}=$ the in situ horizontal stress needed to be overcome when fracturing $(\mathrm{Pa})$

\section{Dimensionless Parameters}

$\tilde{P}=$ dimensionless geofluid pressure in reservoir $\left(\tilde{P}=\left(P-P_{\text {out }}\right) / P^{*}\right)$

$\tilde{t}=$ dimensionless time $\left(\tilde{t}=t \alpha_{\mathrm{r}} / F_{\mathrm{s}}\right)$

$\tilde{T}=$ dimensionless temperature of geofluid $\left(\tilde{T}=\left(T-T_{\text {in }}\right) /\right.$ $\left.\left(\bar{T}_{\mathrm{r}, \infty}-T_{\text {in }}\right)\right)$

$\tilde{T}_{\mathrm{r}}=$ dimensionless temperature of rock block $\left(\tilde{T}_{\mathrm{r}}=\left(T_{\mathrm{r}}-T_{\mathrm{in}}\right) /\left(\bar{T}_{\mathrm{r}}, \infty-T_{\mathrm{in}}\right)\right)$

$\tilde{T}_{\text {out }}=$ dimensionless temperature of geofluid at reservoir outlet $\left(\tilde{T}_{\text {out }}=\left(T_{\text {out }}-T_{\text {in }}\right) /\left(\bar{T}_{\mathrm{r},, \infty}-T_{\text {in }}\right)\right)$

$\tilde{U}=$ dimensionless geofluid velocity in $x$ direction $\left(\tilde{U}=U / V^{*}\right)$

$\tilde{V}=$ dimensionless geofluid velocity in $z$ direction $\left(\tilde{V}=V / V^{*}\right)$

$\tilde{x}=$ dimensionless length in $x$ direction $(\tilde{x}=x / R)$

$\tilde{y}=$ dimensionless length in $y$ direction $\left(\tilde{y}=y / F_{\mathrm{s}}\right)$

$\tilde{z}=\operatorname{dimensionless}$ depth in $z$ direction $\left(\tilde{z}=\left(z-\bar{Z}_{\mathrm{r}}\right) / R\right)$

$\tilde{z}_{\mathrm{r}, \text { in }}=$ dimensionless depth of reservoir inlet $\left(\tilde{z}_{\mathrm{r}, \text { in }}=\left(z_{\mathrm{r}, \text { in }}-\bar{Z}_{\mathrm{r}}\right) / R\right)$

$\tilde{z}_{\text {r,out }}=$ dimensionless depth of reservoir outlet $\left(\tilde{z}_{\mathrm{r}, \text { out }}=\left(z_{\mathrm{r}, \text { out }}-\bar{Z}_{\mathrm{r}}\right) / R\right)$

\section{References}

[1] Wong, K. V., and Tan, N., 2015, "Feasibility of Using More Geothermal Energy to Generate Electricity," ASME J. Energy Resour. Technol. 137(4), p. 041201 .

[2] Tester, J. W., Anderson, B., Batchelor, A., Blackwell, D., DiPippo, R., Drake, E., Garnish, J., Livesay, B., Moore, M. C., Nichols, K., Petty, S., Toksoz, M. N., Veatch, R. W., Baria, R., Augustine, C., Murphy, E., Negraru, P., and Richards, M., 2006, The Future of Geothermal Energy: Impact of Enhanced Geothermal Systems (EGS) on the United States in the 21 st Century, Massachusetts Institute of Technology, Cambridge, p. 209.

[3] Fronk, B. M., Neal, R., and Garimella, S., 2010, "Evolution of the Transition to a World Driven by Renewable Energy," ASME J. Energy Resour. Technol. 132(2), p. 021009. 
[4] DiPippo, R., 2005, Geothermal Power Plants: Principles, Applications and Case Studies, Elsevier, Oxford/New York.

[5] Augustine, C. R., 2009, "Hydrothermal Spallation Drilling and Advanced Energy Conversion Technologies for Engineered Geothermal Systems," Ph.D., thesis, MIT, Cambridge.

[6] Kruger, P., and Otte, C., 1973, American Nuclear Society, Geothermal Energy; Resources, Production, Stimulation, Stanford University Press, Stanford, CA.

[7] O'Sullivan, M. J., Pruess, K., and Lippmann, M. J., 2001, "State of the Art of Geothermal Reservoir Simulation," Geothermics, 30(4), pp. 395-429.

[8] Ishida, T., Chen, Q., Mizuta, Y., and Roegiers, J., 2004, "Influence of Fluid Viscosity on the Hydraulic Fracturing Mechanism," ASME J. Energy Resour. Technol., 126(3), pp. 190-200.

[9] Armstead, H. C. H., and Tester, J. W., 1986, Heat Mining, Methuen, New York.

10] Fox, D. B., Sutter, D., Beckers, K. F., Lukawski, M. Z., Koch, D. L., Anderson, B. J., and J. W. Tester, 2013, "Sustainable Heat Farming: Modeling Extraction and Recovery in Discretely Fractured Geothermal Reservoirs," Geothermics, 46(4), pp. 42-54.

[11] "Engineering Toolbox," http://www.engineeringtoolbox.com/poissons-ratiod_1224.html

[12] Kelkar, S., Lewis, K., Hickman, S., Davatzes, N. C., Moos, D., and Zyvoloski, G., 2012, "Modeling Coupled Thermal-Hydrological-Mechanical Processes During Shear Stimulation of an EGS Well," Thirty-Seventh Workshop on Geothermal Reservoir Engineering, Stanford University, Stanford.

[13] De Simone, S., Vilarrasa, V., Carrera, J., Alcolea, A., and Meier, P., 2013 , "Thermal Coupling May Control Mechanical Stability of Geothermal Reservoirs During Cold Water Injection," Phys. Chem. Earth, Parts A/B/C, 64, pp. 117-126.

[14] Yoon, J. S., Zang, A., and Stephansson, O., 2014, "Numerical Investigation on Optimized Stimulation of Intact and Naturally Fractured Deep Geothermal Reservoirs Using Hydro-Mechanical Coupled Discrete Particles Joints Model," Geothermics, 52(10), pp. 165-184.

[15] Gidley, J. L., 1989, Recent Advances in Hydraulic Fracturing, Society of Petroleum Engineers, Richardson.

[16] Geertsma, J., and De Klerk, F., 1969, "A Rapid Method of Predicting Width and Extent of Hydraulically Induced Fractures," J. Pet. Technol., 21(12), pp. 1571-1581.

[17] Hofmann, H., Babadagli, T., and Zimmermann, G., 2014, "Numerical Simulation of Complex Fracture Network Development by Hydraulic Fracturing in Naturally Fractured Ultratight Formations," ASME J. Energy Resour. Technol., 136(4), p. 042905

[18] The MathWorks, Inc., 2012, Version 2012a, MATLAB, Natick, MA.
[19] Hofmann, H., Babadagli, T., and Zimmermann, G., 2014, "Hot Water Generation for Oil Sands Processing From Enhanced Geothermal Systems: Process Simulation for Different Hydraulic Fracturing Scenarios," Appl. Energy, 113(1), pp. 524-547.

[20] Finsterle, S., Zhang, Y., Pan, L., Dobson, P., and Oglesby, K., 2013, "Microhole Arrays for Improved Heat Mining From Enhanced Geothermal Systems," Geothermics, 47(7), pp. 104-115.

[21] Cerminara, M., and Fasano, A., 2012, "Modeling the Dynamics of a Geothermal Reservoir Fed by Gravity Driven Flow Through Overstanding Saturated Rocks,” J. Volcanol. Geotherm. Res., 233(7), pp. 37-54.

[22] Taleghani, A. D., 2013, "An Improved Closed-Loop Heat Extraction Method From Geothermal Resources,” ASME J. Energy Resour. Technol., 135(4), p. 042904.

[23] McFarland, R. D., and Murphy, H., 1976, Extracting Energy From Hydraulically-Fractured Geothermal Reservoir, Los Alamos Scientific Laboratory, Los Alamos.

[24] C Multiphysics, 2012, Version 4.3 a, comsol, Burlington, MA.

[25] Hu, L., Winterfeld, P. H., Fakcharoenphol, P., and Wu, Y., 2013, "A Nove Fully-Coupled Flow and Geomechanics Model in Enhanced Geothermal Reservoirs," J. Pet. Sci. Eng., 107(7), pp. 1-11.

[26] Zeng, Y., Wu, N., Su, Z., and Hu, J., 2014, "Numerical Simulation of Electricity Generation Potential From Fractured Granite Reservoir Through a Single Horizontal Well at Yangbajing Geothermal Field," Energy, 65(2), pp. 472-487.

[27] Zeng, Y., Su, Z., and Wu, N., 2013, "Numerical Simulation of Heat Production Potential From Hot Dry Rock by Water Circulating Through Two Horizontal Wells at Desert Peak Geothermal Field," Energy, 56(7), pp. 92-107.

[28] Cengel, Y. A., and Ghajar, A. J., 2011, Heat and Mass Transfer: Fundamentals \& Applications, 4th ed., McGraw-Hill, New York.

[29] Li, M., 2013, "Energy and Exergy Analysis of Deep Engineered Geotherma System Energy Extraction and Power Generation," M.S. thesis, Department of Mechanical Engineering and Applied Mechanics, University of Pennsylvania, Philadelphia.

[30] Li, M., and Lior, N., 2014, "Comparative Analysis of Power Plant Options for Enhanced Geothermal Systems (EGS)," Energies, 7(12), pp. 8427-8445.

[31] Klein, S., and Alvarado, F., 2002, Engineering Equation Solver, F-Chart Software, Madison.

[32] "U.S Energy Information Administration," http://www.eia.gov/totalenergy/ data/annual/pdf/sec17_3.pdf 